Issued by Sandia National Laboratories, operated for the United States Department of Energy by Sandia Corporation.

NOTICE: This report was prepared as an account of work sponsored by an agency of the United States Government. Neither the United States Government, nor any agency thereof, nor any of their employees, nor any of their contractors, subcontractors, or their employees, make any warranty, express or implied, or assume any legal liability or responsibility for the accuracy, completeness, or usefulness of any information, apparatus, product, or process disclosed, or represent that its use would not infringe privately owned rights. Reference herein to any specific commercial product, process, or service by trade name, trademark, manufacturer, or otherwise, does not necessarily constitute or imply its endorsement, recommendation, or favoring by the United States Government, any agency thereof, or any of their contractors or subcontractors. The views and opinions expressed herein do not necessarily state or reflect those of the United States Government, any agency thereof, or any of their contractors.

Printed in the United States of America. This report has been reproduced directly from the best available copy.

Available to DOE and DOE contractors from Office of Scientific and Technical Information

P.O. Box 62

Oak Ridge, TN 37831

Prices available from (703) 605-6000

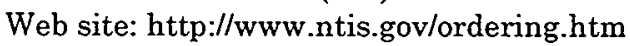

Available to the public from

National Technical Information Service

U.S. Department of Commerce

5285 Port Royal Rd

Springfield, VA 22161

NTIS price codes

Printed copy: A03

Microfiche copy: A01

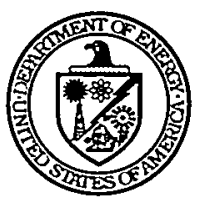




\section{DISCLAIMER}

Portions of this document may be illegible in electronic image products. Images are produced from the best available original document. 


\title{
Monitoring Large Enrichment Plants Using Thermal Imagery from Commercial Satellites: A Case Study
}

\author{
Adam Bernstein \\ Reliability \& Electrical Systems Department \\ Sandia National Laboratories \\ Livermore, California 94551-0969
}

\begin{abstract}
Thermal imagery from commercial satellites is an interesting candidate technology for use as a verification tool for the purpose of monitoring certain types of fissile material production sites. Examples of its potential treaty applications include the Fissile Material Cutoff Treaty (FMCT) or a Fissile Material Production Moratorium. To help determine the capabilities and limitations of such imagery as a monitoring tool, I have examined archived LANDSAT-5 images of the Portsmouth Gaseous Diffusion Plant, a large U.S. uranium-enrichment facility in Ohio. This analysis indicates that large-scale gaseous diffusion plants can very likely be recognized as operational with thermal imagery throughout most of the year in clear weather conditions. It may also be possible to identify certain other large-scale qualitative changes in operations, such as the shut-down of a single process building in a plant, by a comparison of its temperature with the temperatures of neighboring operational process buildings. However, uncertainties in the current data set prevent a definitive conclusion regarding the latter capability.
\end{abstract}

This study identifies intrinsic weaknesses, including vulnerability to countermeasures, that prevent thermal imagery from satellites from being a robust standalone verification 
tool, even for very large enrichment plants. Nonetheless, the imagery may be useful as a trigger for an on-site inspection, to alert and train inspectors prior to an inspection, and possibly to reduce the frequency of on-site inspections required at a given site. It could have some immediate utility for monitoring the two large gaseous diffusion plants the United States and the French plant at Tricastin, and possibly for determining the operational status of two gaseous diffusion plants in China as well - a total of five plants worldwide. The ease of acquisition and modest cost of thermal commercial imagery further increase its attractiveness as a verification tool.

In addition to these basic results, I consider the influence on performance of improvements in spatial resolution in the thermal band expected from new and future platforms. I also discuss the effects of external factors such as convective cooling of the roofs, solar heating, the atmosphere, emissivity changes, and deliberate countermeasures - all of which can adversely affect measurements. 


\section{Contents}

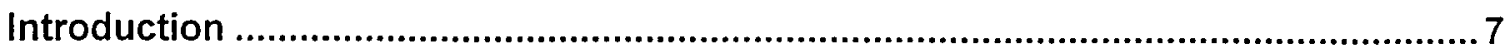

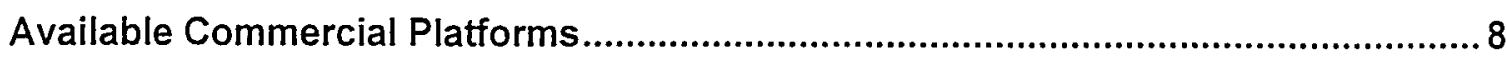

Enrichment Plants Suitable for Monitoring with Thermal Imagery

from Satellites.............................................................................................................

Description of the Portsmouth Gaseous Diffusion Plant............................................ 10

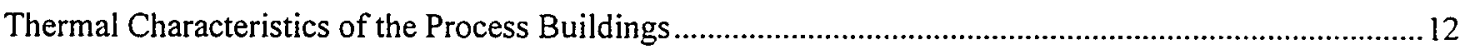

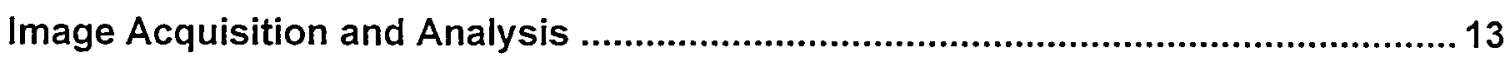

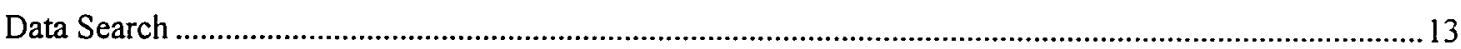

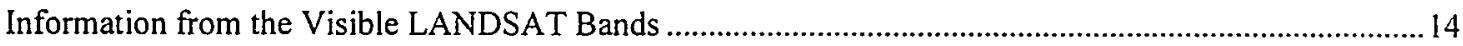

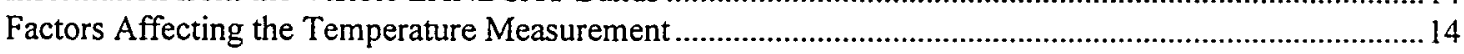

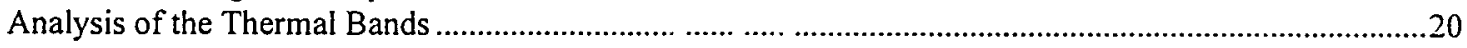

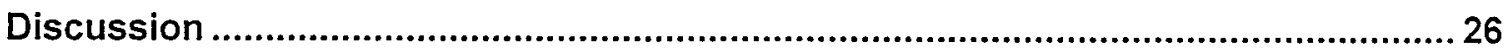

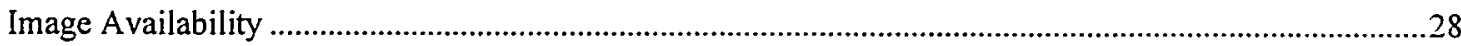

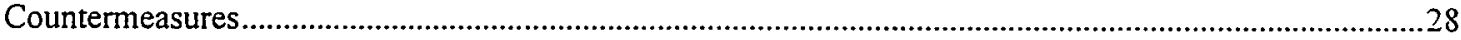

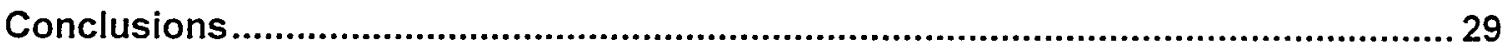

Appendix I: Approximate Changes in the Rooftop Temperature Due to Internal Activity, Solar Heating, and Wind .............................................................................. 30

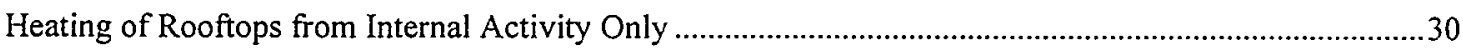

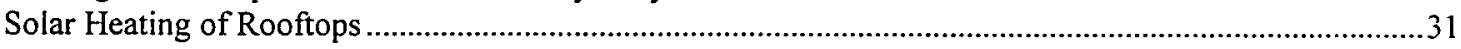

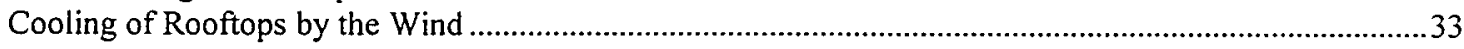

Appendix II: The LANDSAT-5 Temperature Conversion Algorithm ...........................35

Appendix III: The Effects of Pixel Averaging and Resampling On the Temperature Profiles Of Process Building 326 ......................................................... 36

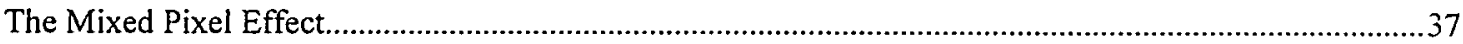

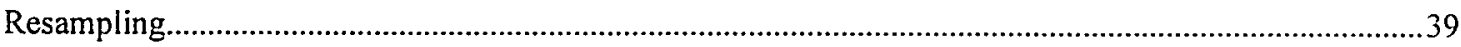

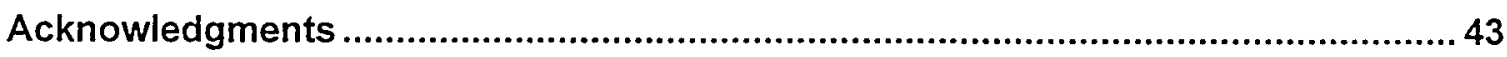

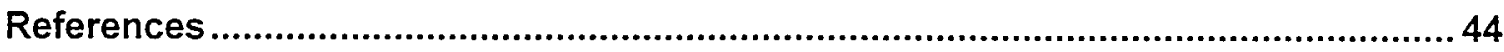




\section{Illustrations}

Figure 1. The Portsmouth gaseous diffusion plant.............................................. 11

Figure 2. An aerial photograph of the Portsmouth plant. ...................................... 12

Figure 3. February 16, 1991, and March 12, 1994 visible LANDSAT images of the Portsmouth enrichment plant.......................................................... 15

Figure 4. A subset of the 1991 and 1994 thermal band showing the Portsmouth plant signature.

Figure 5. Relief images of the thermal output of process buildings derived from the LANDSAT thermal band. A scale factor of 20 has been applied to all pixels in both images to enhance visibility.

Figure 6. The pixels used for the average temperature measurement of the interior area of process building 326 .

Figure 7. A closeup of the 1994 image, showing the resampled pixel granularity and the 12 degree tilt of the pixel relative to the building.

Figure 8. The unresampled $120 \mathrm{~m}$ pixel grid superimposed onto the $2 \times 15$ array of $30 \mathrm{~m}$ pixels at the center of building 326 , used here to define the building average. $\Delta \mathrm{i}$ and $\Delta \mathrm{j}$ are the offsets along the horizontal and vertical grid axes (as measured in units of the unresampled pixel) from pixel $(i, j)$ to the resampled pixel, $\left(i^{\prime}, j^{\prime}\right)$, shown as a black square.

\section{Tables}

Table 1. The area of process buildings at the Portsmouth plant.

Table 2. Ambient conditions at the Portsmouth plant on the days the images were acquired.

Table 3. Mean values of the recorded surface temperature of each process building roof, using a constant interior area of 30 pixels $=24367.5 \mathrm{~m}^{2}$.

Table 4. $T_{i}-T_{j}$, the difference in reconstructed average building roof temperatures in both images.

Table 5 . The rooftop temperatures $T_{\text {roof }}$ of process buildings and their difference from ambient temperature, $\left(T_{\text {roof }}-T_{\text {air }}\right)$, for different values of the internal and ambient process building temperatures $T_{\text {int }}$ and $T_{\text {air }}$

Table 6 . The estimated absorbed solar power incident on flat roofs in the daytime hours before the 9:45 image acquisition time.

Table 7. The expected roof temperature $T_{\text {roof }}$ using Equation 2, compared with the average of the reconstructed values of the rooftop temperature from Table 3 .

Table 8 . The effect of wind on the rooftop temperature 


\section{Monitoring Large Enrichment Plants Using Thermal Imagery from Commercial Satellites: A Case Study}

\section{Introduction}

Reliable monitoring of uranium enrichment facilities, especially those capable of producing high-enriched uranium (HEU), is a key challenge for any regime that would monitor or restrict fissile material production. In this paper I explore the potential of thermal imagery from commercial satellites as a tool for monitoring such facilities.

In particular, I seek to determine whether and to what degree changes can be detected in the operational status of large gaseous diffusion enrichment plants (GDPs) using thermal imagery from commercial satellites. Changes in the operational status might include the start-up of a process building, or a change from the production of uranium enriched to the few percent level to the production of $20 \%$ or greater enriched uranium. For this purpose, I examined archived LANDSAT-5 images of the Portsmouth enrichment plant in southern Ohio over a ten-year period beginning in 1988.

As shown below, existing LANDSAT-5 thermal imagery, as well as imagery from the recently launched LANDSAT-7 satellite, may be helpful in detecting certain large-scale changes in the operational status of GDPs. However, thermal imagery (at virtually any resolution) cannot detect more subtle changes in plant operations - for example, those that might occur if stages within a single process building were reconfigured.

The qualitative change detection capability identified here limits but does not preclude the use of thermal imagery as a monitoring tool. Examples of possible applications include: triggering closer inspections of plant operations; alerting on-site inspectors to possible anomalous activity prior to an inspection; and helping to reduce the frequency of on-site inspections. This last application could be attractive for the United States, since two of the GDPs currently suitable for monitoring with thermal imagery (described below) are located in the United States. Moreover, the modest cost of the commercial 
images (a few hundred dollars per image in the case of LANDSAT-7) increases the attractiveness of the method, even for these limited applications.

Confounding factors such as wind and other atmospheric conditions can degrade the thermal signature and make interpretation difficult. In addition, the host country might attempt to conceal the heat output of the plant in various ways. Further study of both the natural and deliberate changes in the thermal signature is required to determine whether the change detection capability suggested by the current study could be reproduced with confidence in an actual monitoring regime.

In the first sections of this paper I identify the available sources of satellite thermal imagery, and the types of enrichment plants most suitable for monitoring with this imagery. Next I review the relevant characteristics of the Portsmouth plant, and describe the factors influencing the plant temperature measurement. I then analyze two images of the plant. I conclude with a discussion of the capabilities and limitations of thermal imagery from commercial satellites as an FMCT monitoring tool.

\section{Available Commercial Platforms}

The only commercial sources of thermal imagery currently available are the LANDSAT satellites, LANDSAT-5 and LANDSAT-7. This study relies only on LANDSAT-5 data, which has a 120×120 m pixel size. Thus, a typically sized GDP building of a dozen hectares or so is covered by only 10 to 15 pixels. LANDSAT-7 was launched in April of 1999, and has $60 \mathrm{~m}$ spatial resolution in the thermal band ${ }^{1}$, increasing the number of pixels by a factor of 4 . The nominal thermal resolution for both LANDSAT-5 and LANDSAT-7 is around $0.5-1{ }^{\circ} \mathrm{C}$, once atmospheric and other effects are accounted for. ${ }^{2}$ Overall temperature shifts of several Celsius degrees are possible if the systematic temperature effects are not corrected, but will not affect the relative measurements to be used in this study. For this LANDSAT- 5 data set, a resampling procedure implemented by the image supplier may in principle have degraded the resolution somewhat, even for relative measurements, to as much as a few degrees Celsius. This effect, discussed in detail below, is an artifact of the current data set and can be avoided in other LANDSAT5 data sets and other platforms. 
Although not a directly commercial platform, another potential source of imagery is the ASTER imaging system ${ }^{3}$, scheduled for a November 1999 launch with the NASA EOS AM-1 satellite. ASTER has a spatial resolution in each of its five thermal bands of about $90 \mathrm{~m}$. ASTER data will be made publicly available (albeit with some restrictions) through NASA's EOSDIS program. ${ }^{4}$

\section{Enrichment Plants Suitable for Monitoring with Thermal Imagery from Satellites}

Global uranium enrichment capacity is dominated by gaseous diffusion and gas centrifuge technology. With a specific power consumption of about $2400 \mathrm{kWh} / \mathrm{SWU}$, gaseous diffusion is the most energy intensive enrichment method, and GDPs are among the largest roofed buildings in the world. This combination of properties makes them good candidates for monitoring with thermal imagery. In contrast, the energy consumption of a gas centrifuge plant is about 10 times lower than that of a gaseous diffusion plant of equal enrichment capacity. The roof area of a gas centrifuge plant is also about 10 times smaller than that of a diffusion plant of equal capacity. This area corresponds to no more than one unresampled spatial pixel in the LANDSAT-5 thermal band ${ }^{5}$, or about 4 pixels in the LANDSAT-7 thermal band.

There are two large operational GDPs in the United States, the Paducah and Portsmouth plants. France has one operational plant at Tricastin. One or possibly two GDPs operate or have operated in China, at Lanzhou and at Heiping. ${ }^{6}$

Given the comparatively small area and low heat output of other types of enrichment plants, monitoring of enrichment plants with the thermal imagery currently available from commercial sources is essentially restricted to GDPs. The smallest GDP, the Chinese plant at Lanzhou, (approximately $700 \mathrm{~m}$ by $100 \mathrm{~m}$ in size, or six pixels) is barely visible using LANDSAT-5, but would span about 24 pixels in a LANDSAT-7 image.

Using 10 pixels as a rough figure of merit for simple detection of an operating plant, relaxing the restriction to GDPs would require further improvements in the spatial

\footnotetext{
${ }^{\text {a }}$ SWU stand for a Separative Work Unit, a measurement of the enrichment capacity of the plant.
} 
resolution of commercial satellite imagery, by a factor of about two beyond LANDSAT7's 60 m resolution.

\section{Description of the Portsmouth Gaseous Diffusion Plant}

The Portsmouth GDP was a dedicated government HEU production facility until 1992, when it was adapted to the purpose of civil production of low enriched uranium (LEU). The plant produced $\sim 90 \%$ enriched HEU through November 20,1992, after which it began producing LEU enriched to the 4-5\% level. For convenience, I refer to the earlier operational state as the "HEU mode" and the later state as the "LEU mode."

The plant, shown in Figure 1 and Figure 2, has three separate process buildings, numbered 326, 330, and 333. Each building has two floors, with the second floor housing the process equipment. Table 1 shows the area of each process building in hectares and LANDSAT-5 thermal band pixels.

Table 1. The area of process buildings at the Portsmouth plant.

\begin{tabular}{|l|l|c|}
\hline Building & $\begin{array}{l}\text { Roof Area hectares } \\
\left(10^{4} \mathrm{~m}^{2}\right)\end{array}$ & $\begin{array}{l}\text { Roof Area pixels } \\
(120 \mathrm{~m} \times 120 \mathrm{~m})\end{array}$ \\
\hline 333 & 13.0 & $9(2.46 \times 3.70)$ \\
\hline 330 & 12.9 & $9(1.63 \times 5.53)$ \\
\hline 326 & 11.4 & $8(1.40 \times 5.66)$ \\
\hline
\end{tabular}

In either mode, the cascade begins in building 333, which contains 640 stages. The amount of process material is largest in the earlier stages, and the stages in this building are therefore the largest and most energy intensive. Building 330, containing 1100 stages, is the next step in the cascade, enriching the uranium to around the $4-5 \%$ level. In the HEU mode, the final enrichment to more than $90 \%$ was accomplished in building 326 , which housed about 2280 stages. According to plant records, about $85-90$ percent of the stages in this building were shut down in 1994, relative to the number operational in 1991. 


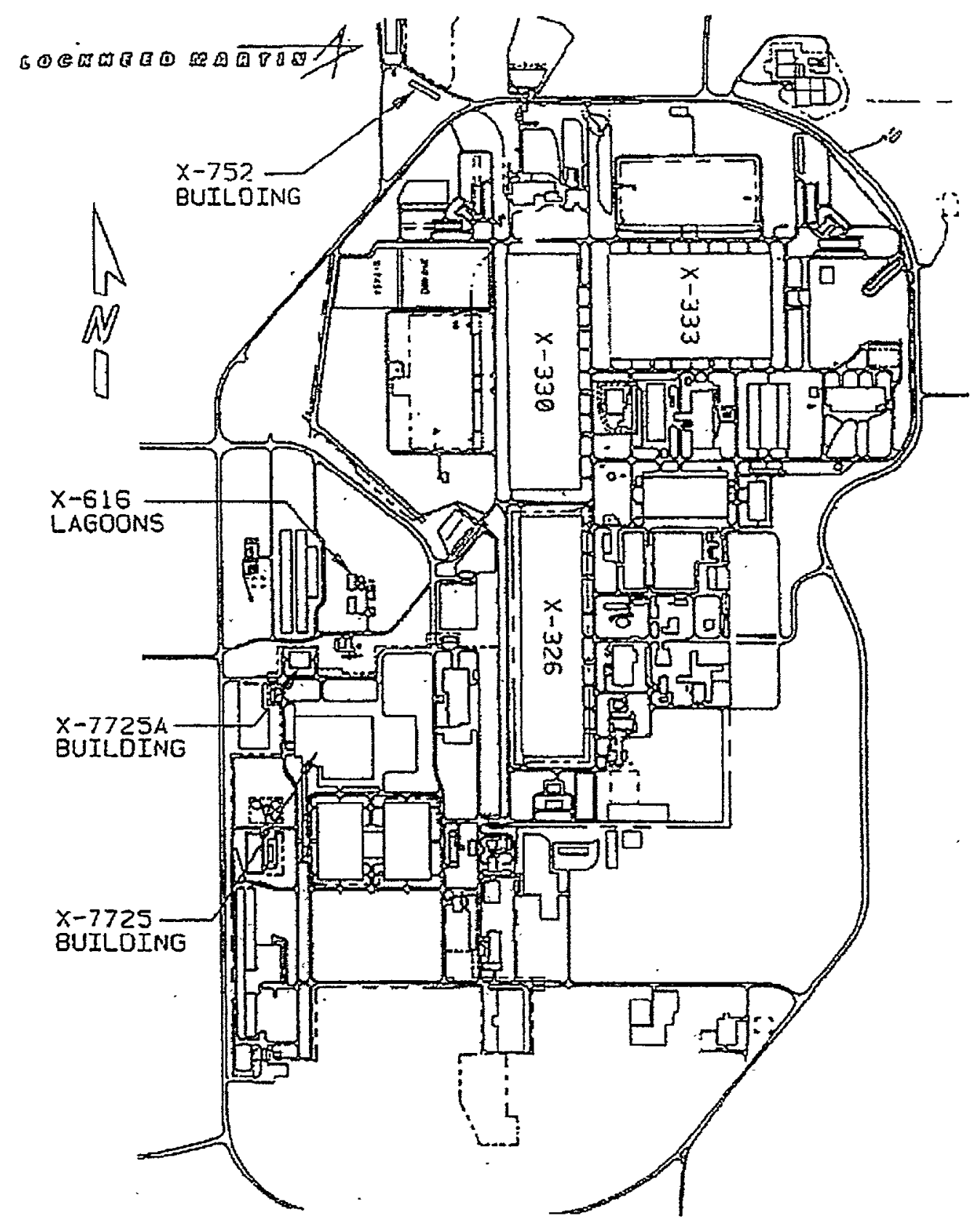

Figure 1. The Portsmouth gaseous diffusion plant. 


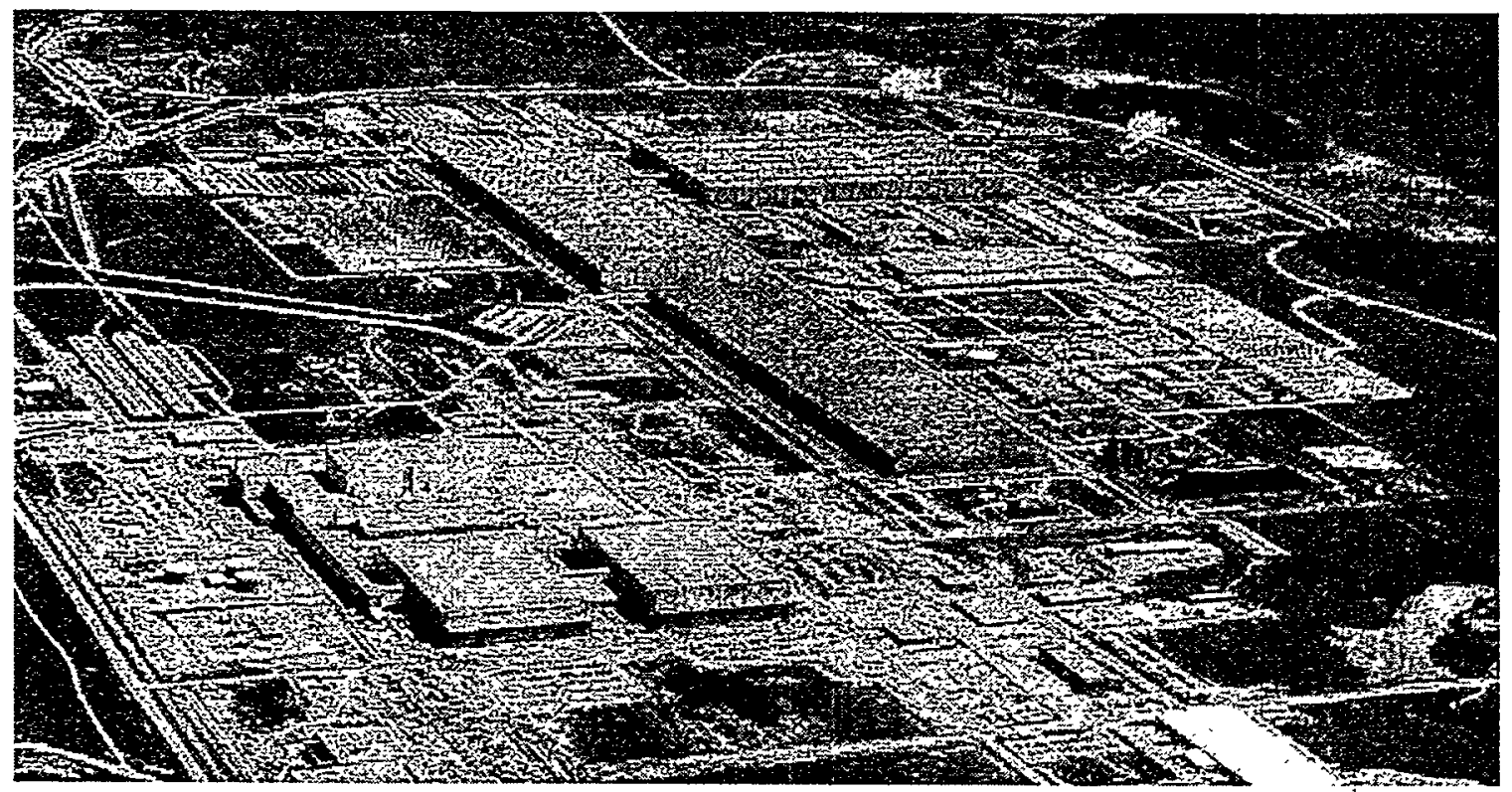

Figure 2. An aerial photograph of the Portsmouth plant. (Courtesy FAS, www.fas.org)

\section{Thermal Characteristics of the Process Buildings}

For this study, the only measurable physical parameter is the temperature of process building roofs, which is related to the emitted radiant energy as measured in the LANDSAT thermal band. The sources of this energy are the stages themselves, heaters (used to maintain the gas temperature in process piping), power supplies, and other building utilities. The roof temperature is also strongly affected by solar heating and by the wind, as discussed below.

Each building has its own recirculating cooling water system connected to an evaporative steam cooling tower. One cooling tower is located near the northwest corner of building 330 and the other two are near the northeast corner of building 333.

Building ventilation is achieved with cooling air pulled in through filters on the ground floor and pushed to the second floor through floor vents and openings in the cell motor bases. Hot air from the second floor is vented through numerous controlled roof vents, lowering the interior ceiling temperature and the rooftop temperature. 
The process building roofs are multi-layers consisting of tar, paper, insulation, and gravel on top of their steel roof decking. The multi-layer is several inches thick, and the top layer is gravel. ${ }^{7}$ The actual value of the roof emissivity was not measured for this study, and standard tables do not provide a thermal emissivity value for gravel. Instead, I use a nominal value for the thermal emissivity of gravel of 0.9 , basing this estimate on the range of values for rough concrete, rock, and brick. ${ }^{8}$

Although precise ground truth information about the actual internal and rooftop temperatures of the process buildings was not available for this study, it is important to compare the estimated size of the temperature increase expected from internal activities with the approximate few ${ }^{\circ} \mathrm{C}$ temperature resolution (for relative measurements) of the satellite. From discussions with Portsmouth officials ${ }^{9}$, and from other sources ${ }^{10}$, I adopt a value of $60^{\circ} \mathrm{C}$ for the internal ceiling temperature. As shown in Appendix I, this internal temperature would produce characteristic rooftop temperatures of about $18{ }^{\circ} \mathrm{C}$ for an outside air temperature of $4{ }^{\circ} \mathrm{C}$, and $41^{\circ} \mathrm{C}$ for an ambient temperature of $35^{\circ} \mathrm{C}$. (absent solar heating). The temperature difference between the rooftops and the ambient temperature arising from internal activity is therefore never less than $5-6{ }^{\circ} \mathrm{C}$ in the worst case (during the summer), and is typically $10-15^{\circ} \mathrm{C}$ or greater. Changes of this magnitude will be easily detectable with any of the platforms described above, including LANDSAT-5.

As shown in Appendix I, solar heating does contribute significantly to the heat load of the rooftops, thereby increasing their temperatures. This effect, though significant in an absolute sense (even at 9:45 AM when the images are acquired), will not obscure the temperature rise caused by internal activity.

\section{Image Acquisition and Analysis}

\section{Data Search}

We searched an online archive of LANDSAT images of the Portsmouth plant. ${ }^{11}$ From 1988 to 1998 , I found about 200 images. I rejected images with more than $20 \%$ cloud cover, for which online previews were unavailable, or which had corrupted data. 50 images remained after this selection process, from which I chose two: one from February 
16 1991, when the plant was operating in HEU mode, and one from March 12 1994, when the plant was operating in LEU mode.

\section{Information from the Visible LANDSAT Bands}

Figure 3 shows images of the plant derived from the LANDSAT visible bands. The process buildings can be seen in both the 1991 and 1994 images, and in all other LANDSAT spectral bands including the thermal. Steam plumes from the cooling towers can also be seen in both images, and reveal a clear difference in wind conditions. The 1991 image shows a breeze blowing in a northeasterly direction, while the 1994 image shows relatively little wind. Weather records on each day (recorded in Waverly, a town about $12 \mathrm{~km}$ north of the site) show a significant difference in the outside air temperature. Table 2 summarizes the weather conditions on each day. As will be seen below, the change in external conditions has an important impact on the thermal signature.

Table 2. Ambient conditions at the Portsmouth plant on the days the images were acquired.

\begin{tabular}{|l|c|c|c|l|}
\hline Date/Time & Mode & $\begin{array}{c}\text { Low temperature } \\
\left({ }^{\circ} \mathrm{C}\right)\end{array}$ & $\begin{array}{c}\text { High temperature } \\
\left({ }^{\circ} \mathrm{C}\right)\end{array}$ & Wind \\
\hline $\begin{array}{l}\text { February 16, 1991 } \\
\text { 9:45 A.M. } \\
\sim 2.4 \text { hours after } \\
\text { sunrise }\end{array}$ & HEU & -15 & -7 & breeze \\
\hline $\begin{array}{l}\text { March 12, 1994 } \\
\text { 9:45 A.M. } \\
\sim 3 \text { hours after } \\
\text { sunrise }\end{array}$ & LEU & 1 & 10 & to NE \\
\hline
\end{tabular}

\section{Factors Affecting the Temperature Measurement}

Radiance is the quantity actually measured by thermal sensors on the satellite. The radiance $R$ is defined as the density of the emitted radiant energy in a given spectral range measured at the satellite in watts per square meter. $\mathrm{R}$ can be related to the roof surface 

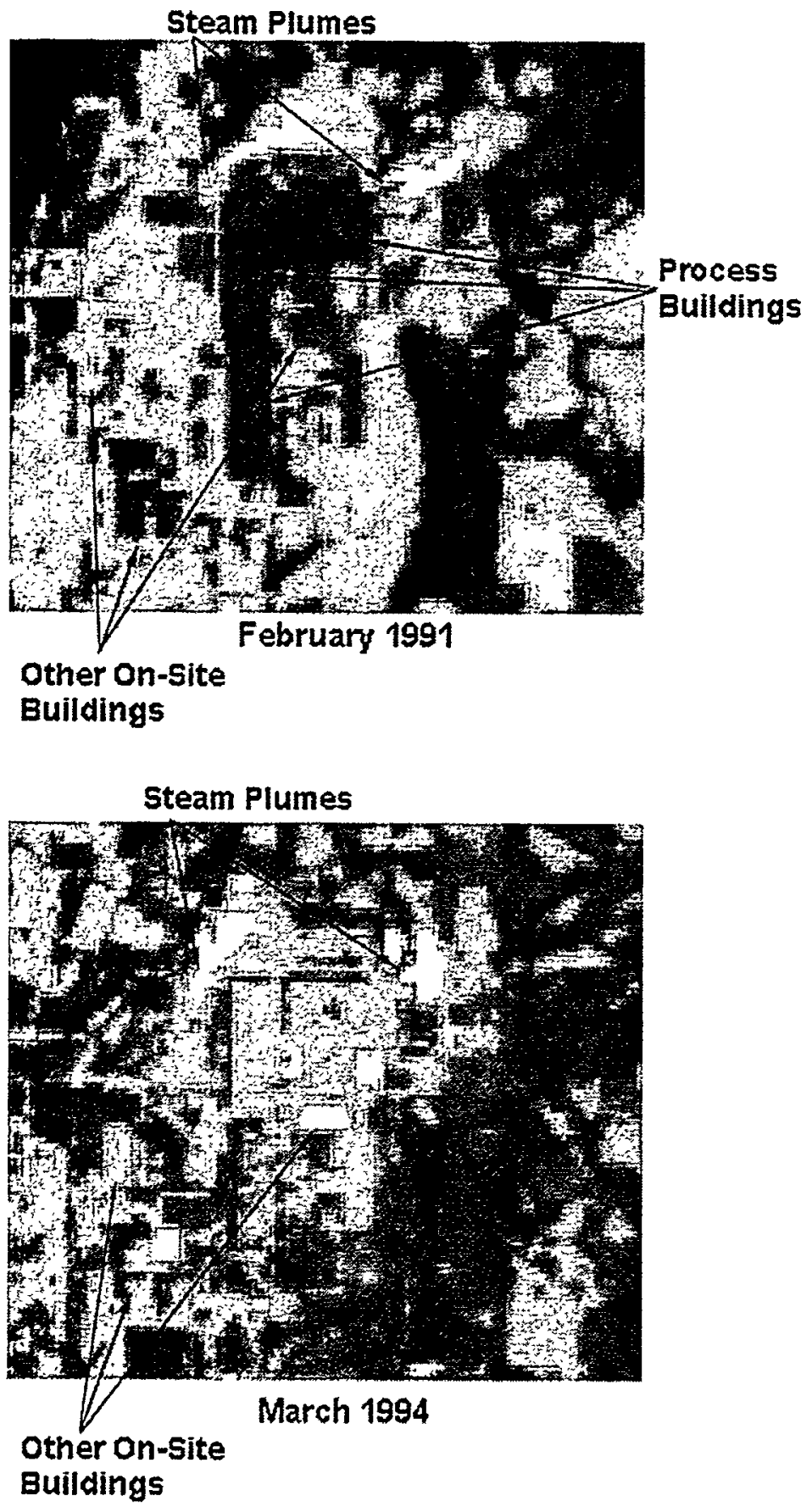

Figure 3. February 16, 1991, and March 12, 1994 visible LANDSAT images of the Portsmouth enrichment plant. Steam plumes from cooling towers can be seen in both images, revealing differing wind patterns. Also shown are relatively large non-process related buildings. 
temperature using a standard algorithm ${ }^{12}$, as described in Appendix II. The goal is to infer activity within the building from the derived roof temperature. However, the temperature can be affected by several factors that do not depend on internal activity: uncertainty in the roof emissivity, atmospheric interference, the effects of finite pixel size and resampling, convection and solar heating. These are discussed in turn below.

\section{Emissivity}

As long as temperature shifts between buildings are measured, rather than absolute temperatures, the precise value of the emissivity is not important. However, the emissivity must remain constant to within a few percent between image acquisitions (or be re-measured for each observation). For example, a five percent shift in emissivity gives about a $2-3^{\circ} \mathrm{C}$ shift in the temperature range $0-50{ }^{\circ} \mathrm{C}$; a one percent emissivity change causes a temperature shift of less than $1{ }^{\circ} \mathrm{C}$. As already described, I have chosen a nominal thermal emissivity value for gravel of 0.9 , constant across buildings and images. In practice, a monitoring regime would have to include an initial characterization of the emissivity of each process building roof, as well as periodic verification that the emissivity had not significantly changed. This could be done during onsite inspections.

If the process building roofs are not resurfaced between images, and accumulations of snow or water are not present on the roof surface, changes in emissivity should arise only from natural wear of the roof materials. If wearing effects are approximately constant between building roofs, the resulting systematic shift in the reconstructed temperature will vanish if temperature differences between buildings and background are used to measure changes in activity, as specified in more detail below.

Since emissivity changes in the visible and thermal bands are correlated, the visible LANDSAT bands can be used to determine whether unusual changes in emissivity between buildings has occurred, and to check for moisture, accumulation of water, or other material on the rooftops. Images with evidence of such buildup would have to be rejected for further analysis. In addition, evidence of permanent emissivity changes taken from the visible band might themselves be used to trigger further inspection. 


\section{Atmospheric Effects}

Variations in the transmittance of the atmosphere (due to humidity and temperature changes) and variation in the background radiance from the atmosphere both affect the apparent temperature of surface objects. The shift depends on the region of the Earth, the surface temperature itself, and on the season. Atmospheric models validated with comparisons to ground truth data have been developed to characterize the effect. As long as atmospheric effects are uniform across the buildings and their surroundings, these absolute shifts will vanish in the relative temperature measurements used in this study (defined below). I assume this is true for this image set, and make no corrections for atmospheric effects.

In general, low humidity, cloud and haze-free measurements are preferable for this type of analysis. In a monitoring regime, local weather data could be used to help select suitable images. In principle, local radiosonde data taken at the time of image acquisition if desired, or atmospheric model corrections could be used to provide a more accurate temperature reading. Past studies indicate an absolute reconstruction accuracy of about $0.5^{\circ} \mathrm{C}$ can be achieved with LANDSAT-5 data when images are corrected for atmospheric effects. ${ }^{13}$

\section{Pixel Smearing, Resampling Error and Geocorrection}

There are two main error sources associated with the large pixel size of the LANDSAT-5 data. First, the measured radiance within each $120 \mathrm{~m}$ pixel is an average over its area. Because of the lower radiance values of the cooler areas surrounding the buildings, the averaging process will systematically decrease the apparent radiance of the building. This so-called "mixed-pixel" effect is potentially largest in the narrowest building (326), which is $1.4120 \mathrm{~m}$ pixels wide. Second, in the data used for this study was resampled or smoothed with a cubic convolution resampling algorithm, as described in Appendix III. In the images used here, the resampling process subdivides the raw $120 \times 120 \mathrm{~m}$ pixels into $28.5 \times 28.5 \mathrm{~m}$ pixels. The interpolation algorithm used in the subdivision can change the apparent value of the radiance of pixels within the building perimeter. Without access to the raw unresampled data, it is important to estimate the approximate size and sign of the changes in temperature induced by combined effects of pixel mixing and the 
resampling process. In Appendix III, I derive a rough bound on this error for the current data set.

It is important to emphasize that the averaging and resampling problems described here are particular to the LANDSAT-5 imagery, and will be nearly or completely eliminated in LANDSAT-7 imagery for target sizes similar to the GDPs considered here, for two reasons. First, the LANDSAT-7 pixel area is 4 times smaller than the LANDSAT-5 pixel, so that each building extends across multiple pixels in both dimensions. Second, LANDSAT-7 data can be delivered unresampled or using a nearest-neighbor resampling algorithm. In both cases, the original radiance values of pixels are unaltered, so that neither resampling nor the mixed pixel effect will alter derived temperature values. This conclusion holds for any regime relying on LANDSAT-7-like imagery.

\section{Wind}

Wind and the process building venting system can conspire to reduce the building rooftop temperatures. In Appendix I I estimate that a steady uniform $6.7 \mathrm{~m} / \mathrm{sec}(15 \mathrm{mph})$ wind could reduce all reconstructed rooftop temperatures by about $15^{\circ} \mathrm{C}$. As will be shown, the buildings could still be seen above background even with those conditions. However, unlike previous effects, it is unreasonable to expect the effect of wind to be uniform across all buildings. To account for the effects of convection in an accurate way, detailed knowledge of the convective properties of the surface and of local wind conditions at the time of overflight would be required. Because a realistic monitoring regime using satellite data should require only minimal input of ground truth information, this information cannot be expected to be available. In practice, this may mean that images with too much wind would have to be discarded as unreliable. If necessary, the steam emerging from the cooling towers, or local ground truth measurements could be used to select images with little wind.

\section{Solar Heating}

In Appendix I, I calculate approximate contributions to the rooftop heating from solar and internal sources. About one hour or so after sunrise, solar heating begins to contribute significantly to the total heat load in the process building roofs. As shown in Appendix I, 
the internal activity causes a temperature rise of at least $5{ }^{\circ} \mathrm{C}$, and typically $10-15^{\circ} \mathrm{C}$ or more throughout most of the year. Solar heating can contribute another $10-15^{\circ} \mathrm{C}$ to the temperature difference from background, but will never completely obscure the effect on the rooftop temperature from internal activity. As confirmation, nighttime or early morning images can be acquired if necessary, in which case solar effects are reduced or absent.

Differences between building temperatures could be brought about by selective shading of the rooftops from clouds, haze or other effects, or by non-uniform solar absorptivities. However, such changes would not effect the basic capability of determining the overall operational status of the plant.

\section{Choosing Appropriate Metrics}

We must choose metrics that reduce the error caused by the above sources and depend minimally on ground truth, but still capture essential information about changes in building activity. The above discussion of errors shows that it is inappropriate to directly compare the reconstructed temperature of each building across images, because wind, solar heating, the ambient temperature, and other factors can shift the absolute value of the temperature even when there are no changes in building activity.

Thermal imagery may be expected to fulfill two monitoring functions: first to detect operational buildings as heat islands in a relatively cool surrounding sea; and second, possibly, to detect differences between building heat outputs that are indicative of changes in operations within the buildings. Useful metrics for these purposes are:

- $T_{i}-T_{0}$, where $T_{i}$ is the average reconstructed surface temperature of the ith process building and $\mathrm{T}_{0}$ is the scene average or nearby ground temperature; and,

- $T_{j}-T_{j}$, where $T_{i}$ and $T_{j}$ are the average reconstructed surface temperatures of the ith and jth process buildings.

$T_{i}-T_{0}$, the roof temperature relative to background, can be used to determine whether process buildings are heated above the level induced by solar effects alone, providing evidence that internal activity is taking place. A comparison across images of the second metric, $T_{i}-T_{j}$, can be used to look for changes in heating with time between buildings. 
Generally, the use of temperature differences within images should remove the effect of overall shifts in the data, such as might be caused by a change in the ambient temperature, by (uniform) atmospheric interference or by uniform natural degradation of the emissive properties of the roofs. However, non-uniform changes in the emissivity and atmospheric properties are possible, and could result in misinterpretation of the image. Moreover. without ground truth measurements, a nominal value for the emissivity must be assumed in order to reconstruct building temperatures.

\section{Analysis of the Thermal Bands}

\section{Qualitative Identification of the Process Buildings}

Figure 4 shows the LANDSAT-5 thermal images of the plant and the surrounding area for both 1991 and 1994. The set of process buildings is identifiable above the surrounding background. The three process buildings 326,330 and 333 can be clearly seen in the center of each image.

This qualitative identification is based only on the different radiance values of the buildings and the background, and does not depend on any assumptions about the emissivity or the temperature calibration. Overall, the rooftop radiance in the "HEUmode" 1991 image is lower than in the "LEU-mode" 1994 image. This is due to the significantly lower ambient temperature and heavier wind conditions in the earlier image.

The 1991 image provides useful evidence of the possible adverse effects of wind on the thermal radiative signature. In the 1991 image, turbulent convection due to the wind (seen in the visible bands) blurs and degrades the thermal signatures of the process buildings. Steam emerging from the cooling towers northeast and northwest of the process buildings is spread by the northeasterly wind. This effect could obscure temperature differences if the wind were to blow steam directly across the process building roofs. In the 1994 thermal image the effects of the wind are smaller and the building edges appear sharper, a difference consistent with the different wind patterns evident in the visible bands. 

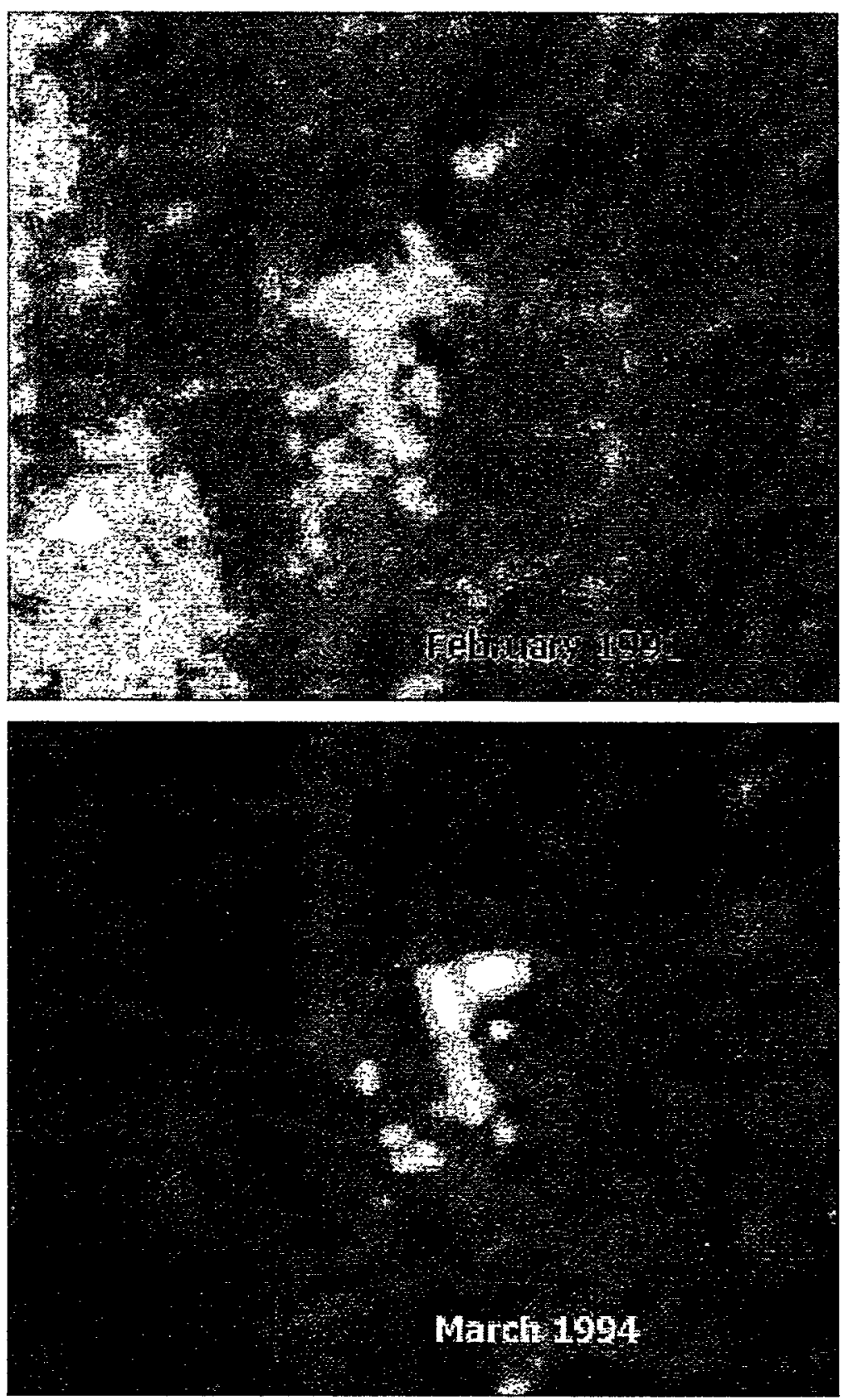

Figure 4. A subset of the 1991 and 1994 thermal band showing the Portsmouth plant signature. In the lower left corner, the markedly different relative values of the radiance of the nearby Scioto River can be seen. 
To further refine the analysis, I consider a perspective relief map made from the thermal band. shown in Figure 5. This image reveals more detail about the thermal signatures of the process buildings and immediate surroundings in 1991 and 1994. The height of each feature is proportional to the raw pixel value in the thermal band, with a scaling factor of 20 applied to enhance the contrast. The dark areas in the image, located near building boundaries indicate sharp changes in the radiance.

There is a qualitative appearance of variation in radiance between process buildings in the 1994 image, while in the 1991 image all buildings appear to be at roughly the same radiance values. In the 1994 image, the average radiance of building 326, in which a significant reduction in activity is known to have occurred, has dropped relative to the other two buildings. Building 333, in which little change in activity has occurred, has higher radiance values than its neighbors.

While the change in the relative radiance values of the buildings is consistent with ground truth, a more quantitative analysis is required to better understand its significance. For this purpose I reconstruct the temperatures of the process building rooftops, and use the relative metrics defined above.

\section{Reconstructed Temperatures of the Process Buildings}

An identical temperature reconstruction procedure was followed for both images. The building perimeters were first defined using the visible and near infrared bands. A uniform central interior area was defined for each building, consisting of 30 resampled $28.5 \times 28.5$ m pixels. A standard algorithm, described in Appendix II, was then used to convert the radiance values of each pixel within this area to temperature values. The

procedure was performed on data without geocorrection, so that the only data-related effects are the mixed pixel and resampling effects previously discussed. The temperature is not corrected for any uniform shifts discussed earlier, and assumes a nominal emissivity value for gravel of 0.9 . 

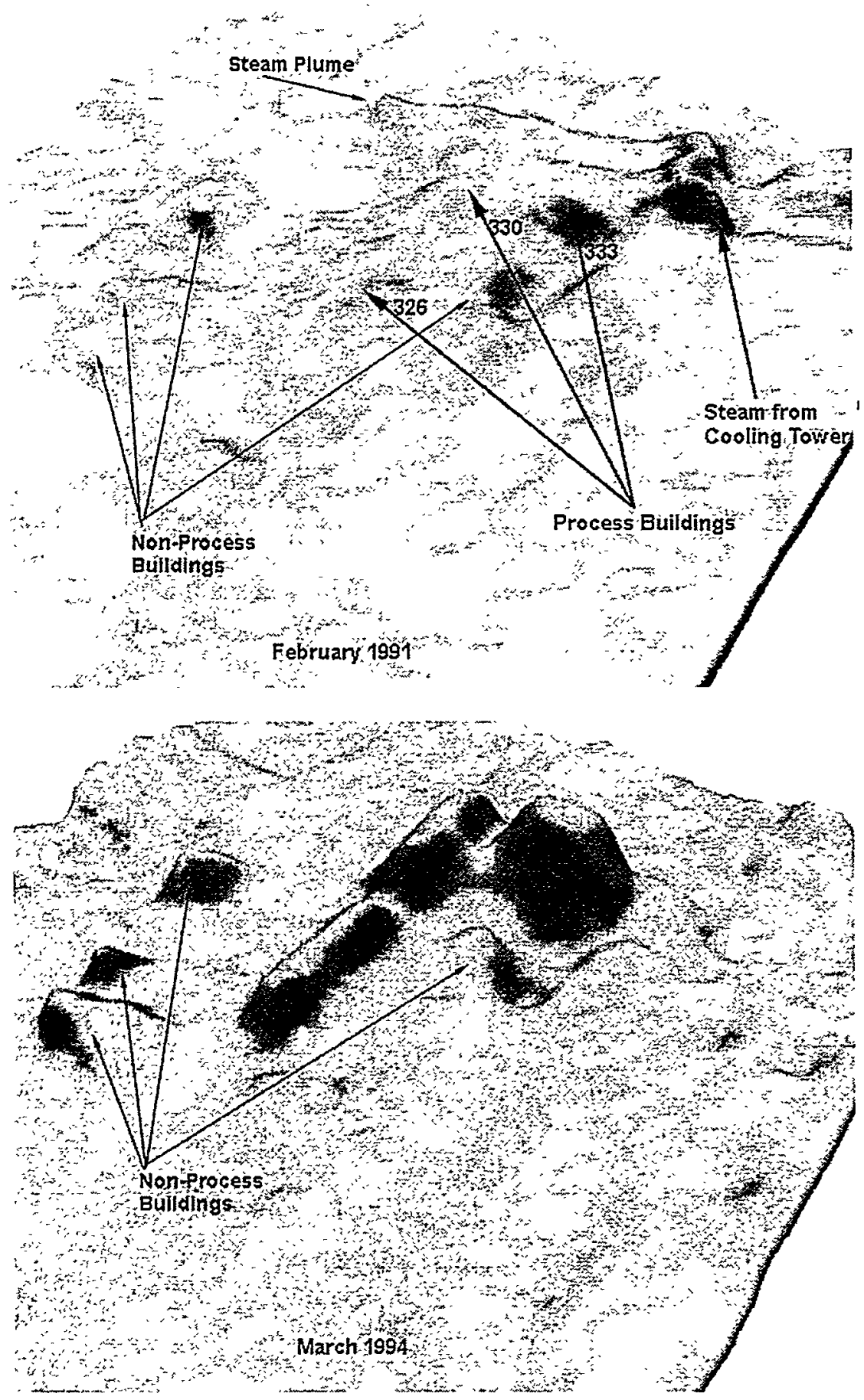

Figure 5. Relief images of the thermal output of process buildings derived from the LANDSAT thermal band. A scale factor of 20 has been applied to all pixels in both images to enhance visibility. 
Table 3 shows the average surface temperature and the surface temperature relative to background for each building and for both images. The most significant potential nonuniform systematic shift is from resampling and pixel averaging, which could induce as much as a $\sim 2{ }^{\circ} \mathrm{C}$ downward shift in the reconstructed temperature. This effect is likely to be largest in building 326. In addition, a non-uniform change in emissivity of 5 percent for any building could result in a $2-3{ }^{\circ} \mathrm{C}$ shift in its temperature, opposite in sign to the emissivity shift. The last column of the table shows, $T_{\mathbf{i}}-T_{0}$, where $T_{0}$ is the scene average temperature and $T_{i}$ the average surface temperature of the ith building. The last row of the table shows the entire scene average temperatures for both images. The scene average temperatures are within their respective ambient temperature ranges, shown in Table 2 , providing a rough check on the temperature calibration.

Table 3. Mean values of the recorded surface temperature of each process building roof, using a constant interior area of 30 pixels $=24367.5 \mathrm{~m}^{2}$. The emissivity is assumed to have a nominal value of 0.9 throughout. A nonuniform systematic shift of as much as 2 ${ }^{\circ} \mathrm{C}$ can occur from the combination of resampling and mixed pixel effects. In addition, nonuniform changes in the emissivity at the 5 percent level could cause shifts of $2{ }^{\circ} \mathrm{C}$ (See text above).

\begin{tabular}{|c|c|c|c|c|c|}
\hline \multirow[t]{3}{*}{$\begin{array}{l}\text { Building } \\
\text { number }\end{array}$} & \multirow[t]{3}{*}{$\begin{array}{l}\text { pixels used } \\
\text { in mean } \\
(28.5 \times 28.5 \mathrm{~m})\end{array}$} & \multicolumn{4}{|c|}{$\begin{array}{l}\text { Building roof mean temperature and difference } \\
\text { from background }\left(T_{1-} T_{0}\right) \\
\qquad(\varepsilon=0.9)\end{array}$} \\
\hline & & \multicolumn{2}{|l|}{1991 image } & \multicolumn{2}{|l|}{1994 image } \\
\hline & & $\begin{array}{lc}T_{\mathrm{i}} & \text { error } \\
\left({ }^{\circ} \mathrm{C}\right) & \text { (stat. only) }\end{array}$ & $T_{\mathrm{i}-} \mathrm{T}_{0}$ & $\begin{array}{ll}\mathrm{T}_{\mathrm{i}} & \text { error } \\
\left({ }^{\circ} \mathrm{C}\right) & \text { (stat. only) }\end{array}$ & $\mathrm{T}_{\mathrm{i}-\mathrm{T}_{0}}$ \\
\hline 333 & $(3 \times 10$ pixels $)$ & $4.1 \pm 0.3$ & +11.8 & $26.1 \pm 0.7$ & +21.7 \\
\hline 330 & (2x15 pixels) & $3.9 \pm 0.4$ & +11.6 & $24.1 \pm 0.5$ & +19.7 \\
\hline 326 & (2x15 pixels) & $3.4 \pm 0.2$ & +11.1 & $22.1 \pm 0.6$ & +17.7 \\
\hline $\begin{array}{l}\text { reconstructed } \\
\text { scene } \\
\text { average } \\
\text { temperature } \\
(\varepsilon=1)\end{array}$ & & \multicolumn{2}{|c|}{$\begin{array}{l}-7.7 \\
\text { (measured outside temp: } \\
\text { low }=-15 \\
\text { high }=1 \text { ) }\end{array}$} & \multicolumn{2}{|l|}{$\begin{array}{l}4.4 \\
\text { (measured outside temp. } \\
\text { low }=-7 \\
\text { high }=10 \text { ) }\end{array}$} \\
\hline
\end{tabular}

Table 4 shows the difference in temperature between buildings, with statistical error added in quadrature, for both images. If the systematic shifts are in fact constant across 
buildings and images, then the 1994 image reveals a $\sim 4{ }^{\circ} \mathrm{C}, 4$ standard deviation shift in the temperature of building 326 relative to 333 , when compared to the 1991 temperature difference between the same pair of buildings. The differences between the other two pairs of buildings are smaller, about $2{ }^{\circ} \mathrm{C}$. The apparent relative drop in temperature in building 326 is qualitatively consistent with ground truth, since about 90 percent of the stages in building 326 are known to be non-operational.

Table 4. $T_{i}-T_{j}$, the difference in reconstructed average building roof temperatures in both images. The systematic effect due to resampling may not be uniform, and could reduce the temperature differences with building 326 by around $2{ }^{\circ} \mathrm{C}$. This could eliminate the apparent relative difference in the buildings.

\begin{tabular}{|c|c|c|}
\hline \multirow[t]{3}{*}{$\begin{array}{l}\text { Building } \\
\text { numbers } i, j\end{array}$} & \multicolumn{2}{|c|}{$\begin{array}{l}\text { Difference in building roof mean temperatures }\left(T_{i}-T_{i}\right) \\
(\varepsilon=0.9)\end{array}$} \\
\hline & 1991 image & 1994 image \\
\hline & $\begin{array}{lll}\left.{ }^{\circ} \mathrm{C}\right) & \text { error } & \\
& \text { (stat.) } & \text { resampling shift }\end{array}$ & $\begin{array}{ll}\left.{ }^{\circ} \mathrm{C}\right) & \text { error } \\
& \text { (stat. only) resampling shift }{ }^{2}\end{array}$ \\
\hline 333,330 & $0.2 \pm 0.5-1$ & $2.0 \pm 0.9-$ \\
\hline 330,326 & $0.4 \pm 0.5-1$ & $2.0 \pm 0.8-$ \\
\hline 333,326 & $0.6 \pm 0.4-1$ & $4.0 \pm 1.0-1.0$ \\
\hline
\end{tabular}

a. see Table caption and text.

Because of the apparent consistency between the image analysis and ground truth, one possible conclusion is that the relative temperature change in building 326 from 1991 to 1994 is in fact the effect of the large-scale change in operations. However, there are several difficulties with this interpretation. First, the $1-2{ }^{\circ} \mathrm{C}$ effect of resampling may have produced some of the apparent drop in the temperature of building 326 in the 1994. Second, the effect of wind is considerable in the earlier image, and may not be constant across buildings. Thus the earlier image may not accurately reflect the true temperature profile of the $1991 \mathrm{HEU}$ mode of operation. For example, operations in buildings 330 and 333 are supposed to be largely unchanged, yet there is a temperature difference (albeit smaller in scale) between these two buildings in the 1994 image, which could have been obscured by wind effects in the earlier image. In an actual monitoring regime, the earlier image would probably have to be rejected as unreliable. Third, there is the possibility of 
non-uniform changes in the emissivity between the two buildings between 1991 and 1994. In the present case, a 6 percent change in emissivity of building 326 relative to building 333 would be sufficient to account for the change in reconstructed temperature. Finally. if the transmissive properties of the atmosphere were non-uniform above the buildings, the temperature profile could be distorted by as many as several degrees Celsius, sufficient to account for the measured temperature change. With haze free, low humidity conditions, atmospheric effects can be expected to be uniform across the areas of interest here.

In sum, a significant change in the relative mean temperatures of the buildings (i.e., a change correlated to the changes in building activity known from ground truth) can be inferred from the images only if the effects of resampling, pixel mixing, wind and atmospheric interference are uniform across buildings in each image, and only if emissivity changes are constant across both buildings and images. This prevents conclusive use of the relative temperatures of the buildings $\left(\mathrm{T}_{i}-\mathrm{T}_{\mathrm{j}}\right)$ in the current case. It does not affect the capability of recognizing any particular building as operational in comparison with background using the metric $\left(\mathrm{T}_{\mathrm{i}}-\mathrm{T}_{0}\right)$.

\section{Discussion}

Given that the process buildings are clearly visible in the thermal bands of both images, the above analysis shows that thermal imagery from commercial satellites can reveal that a GDP appears "hot" relative to surroundings, and by implication that the shut-down status of a plant could be identified. In both the 1991 and 1994 images, independent ground truth information indicates that activity is taking place in all three process buildings, and in both cases, the buildings appear significantly hotter than background well above the few Celsius degree limits imposed by resolution, and even when the effects of solar heating are accounted for (as indicated in Appendix I). However, the current image set does not directly reveal how any of the buildings would look in the absence of internal activity.

Because a significant proportion of the rooftop heat load is from the sun, even a completely shutdown building would have a temperature well above the surrounding 
background. This is simply due to the fact that the hollow buildings do not absorb and dissipate heat as efficiently as the surrounding earth, which is an effective heat sink. Nighttime or early morning thermal imagery, might be used to minimize the effects of solar heating and confirm the source of the effect. But even without such imagery, the 6 to $20{ }^{\circ} \mathrm{C}$ increases in roof temperatures induced by internal activity alone (Appendix $\mathrm{I}$ ) can be clearly seen with existing and future satellite thermal images.

The analysis also suggests, but does not prove, that thermal imagery may be able to reveal that a process building a few hectares in size has been shut down, or nearly so, by examining its temperature relative to other process buildings and to surroundings before and after the shut-down. However, because of the unfavorable wind conditions in the earlier image, and because of the possibility of non-uniform changes across buildings in the principle sources of error (resampling/pixel averaging, atmospheric transmission, and emissivity) I cannot definitively conclude from the current set of images that this is possible.

In a future study (or an actual regime) three important conditions, all in principle achievable, would have to be fulfilled in order to conclude definitively that a change in the observed relative rooftop temperatures had occurred. First, occasional measurements of the emissive properties of the roofs would be required, to ensure that the observed effects were not due to non-uniform emissivity changes. Second, only images in which clear, calm, low haze and humidity conditions prevail could be accepted for analysis. Third, the effects of pixel averaging and resampling would have to be minimized by using higher resolution data and a different (or no) resampling method. The fourfold decrease in pixel area and nearest-neighbor resampling option available for LANDSAT-7 images will allow for more accurate monitoring, by largely eliminating mixed pixel and resampling effects. Taken together, these refinements would probably allow detection of a several degree shift in relative temperature between process buildings with thermal imagery from satellites. 
In addition to these requirements, acquisition of nighttime thermal imagery would be useful for removing or minimizing the significant effects of solar heating on the rooftops. Study of such imagery would be a useful follow-on to the current analysis.

\section{Image Availability}

This study found a total of about five candidate images per year at this site, after rejection of cloudy and otherwise unsuitable images. This figure may be an underestimate, since not all of the archived images were available for previewing in the online search engine used for this study. The maximum possible rate of daytime image acquisition-if LANDSAT-7 images were to be used in a monitoring regime-is about 22 per year. This rate would double if the use of nighttime imagery proved feasible. Given that major changes in operations at a GDP, such as the restart of a process area, will in practice take at least several months, a repeat rate of five to ten clear images per year appears frequent enough to ensure that such changes do not go undetected.

\section{Countermeasures}

While identification of a large-scale expansion at a GDP with thermal imagery appears possible at some level, there are a variety of ways to deliberately alter roof temperatures so as to hide the effects of a change in plant operations. Some examples include:

- Returning enriched product from the end of an LEU cascade to its initial stages, reducing the requirements for additional stages. This process is known as batch recycle. ${ }^{b}$

- the presence of unrelated heat sources in or near the process building;

- strategic placement of process cooling towers;

- changes in the emissivity of the process building roofs;

- changes in building cooling or insulation, and;

- removal of heat to other areas of a multipurpose plant to disguise increased activities in process buildings.

All of these steps could severely complicate thermal monitoring of GDPs by satellites.

\footnotetext{
${ }^{b}$ It should be noted that this type of change is difficult to accomplish in large gaseous diffusion plants, primarily because of the large inventories of product in the cascade and the long time required to achieve equilibrium in the system.
} 


\section{Conclusions}

The current analysis indicates that there may be some limited utility of thermal satellite imagery as a companion monitoring technology in a regime that monitors fissile material production. There are five GDPs worldwide for which the method might have some immediate utility. While LANDSAT-7 will improve the monitoring capability for these plants, it will not allow the expansion of the method to gas-centrifuge plants. As discussed earlier, this would require a factor of 2 or so improvement in spatial resolution beyond LANDSAT-7 (assuming a minimum detectability requirement of ten pixels). Moreover, some ground truth data, most notably periodic measurements of the emissivity of the building roofs, would be required to validate any observed change.

With those reservations, thermal imagery can still potentially fulfill three useful monitoring functions for any of the GDPs mentioned. It could help reduce the frequency of on-site inspections, prepare inspectors for an imminent site visit, and possibly serve as a trigger for an on-site inspection or an investigation by some other means. In addition, the utility of the method is enhanced by the low cost of the data, a few hundred dollars per image in the case of LANDSAT-7. However, it is clear from the current study that existing thermal imagery cannot be expected to be a robust stand-alone monitoring tool, but should instead be seen as one element in a comprehensive verification regime.

Because of the relative low quality of the 1991 image used in this study, additional review of a wider data sample, including nighttime imagery, and plants at different sites is required for a more definitive evaluation of the capabilities of thermal imagery. This should be possible through the use of the higher resolution, lower cost LANDSAT-7 platform. 


\section{Appendix I: Approximate Changes in the Rooftop Temperature Due to Internal Activity, Solar Heating, and Wind}

Here I derive a rough estimate of the expected temperature increase of the rooftop caused by internal activity alone, and then consider the additional effects of solar heating and wind. The calculations demonstrates that internal activity contributes significantly to the total heat load in the morning hour (9:45 A.M.) when the LANDSAT images are acquired, even when the effects of sun and wind are included.

\section{Heating of Rooftops from Internal Activity Only}

Equating the heat flow through the roof, $Q_{\text {roof }}$, to the heat flow by convection and radiation into the ambient air, $Q_{\text {air }}$, gives:

1) $Q_{\text {roof }}=K \times\left(\frac{T_{\text {int }}-T_{\text {roof }}}{\Delta x}\right)=Q_{\text {arr }}=C \times\left(T_{\text {roof }}-T_{\text {air }}\right)+\varepsilon \sigma\left(T_{\text {roof }}{ }^{4}-T_{\text {air }}{ }^{4}\right)$,

with

$\varepsilon \quad=0.9 \quad \rightarrow$ the roof thermal emissivity;

$\sigma \quad=5.667 \times 10^{-8} \mathrm{~W} /\left(\mathrm{m}^{2}{ }^{\circ} \mathrm{K}^{4}\right) \quad \rightarrow$ the Stefan-Boltzmann constant;

$\Delta \mathrm{x} \quad=0.1 \mathrm{~m} \quad \rightarrow$ the roof thickness ${ }^{\mathrm{c}}$;

$\mathrm{K} \quad=0.5 \mathrm{~W} /\left(\mathrm{m}^{\circ} \mathrm{C}\right) \quad \rightarrow$ the roof heat conductivity;

$\mathrm{C} \quad=10 \mathrm{~W} /\left(\mathrm{m}^{2}{ }^{\circ} \mathrm{C}\right) \quad \rightarrow$ the heat transfer coefficient for still air.

This equation assumes no solar heating and that the air above the roof is still. The value of $\mathrm{K}$ is chosen as that of a fairly good insulator, while the heat transfer coefficient is a representative value for free convection in air $^{14}$.

$T_{\text {Int }}$ and $T_{\text {air }}$ are the interior temperature of the building at the ceiling, and the ambient temperature above the building respectively. From references 9 and 10, I adopt a 60-80 ${ }^{\circ} \mathrm{C}$ range for the interior temperature. Substituting a range of reasonable values for $T_{\text {arr }}$, and solving for the roof temperature gives the values for $T_{\text {roof }}$ shown in Table 5

\footnotetext{
${ }^{c}$ The roof consists of "a few inches" of composite material, according to Portsmouth site officials.
} 
Table 5. The rooftop temperatures $T_{\text {roof }}$ of process buildings and their difference from ambient temperature, ( $\left.T_{\text {roof }}-T_{\text {arr }}\right)$, for different values of the internal and ambient process building temperatures $\mathrm{T}_{\text {int }}$ and $\mathrm{T}_{\text {air. }}$.

\begin{tabular}{|c|c|c|c|}
\hline $\mathrm{T}_{\text {int }}\left({ }^{\circ} \mathrm{C}\right)$ & $\mathrm{T}_{\text {air }}\left({ }^{\circ} \mathrm{C}\right)$ & $\mathrm{T}_{\text {roof }}\left({ }^{\circ} \mathrm{C}\right)$ & $\left(\mathrm{T}_{\text {roof }}-\mathrm{T}_{\text {air }}\right)\left({ }^{\circ} \mathrm{C}\right)$ \\
\hline 60 & 4 & 18 & 14 \\
\hline 60 & 15 & 26 & 11 \\
\hline 60 & 35 & 41 & 6 \\
\hline 80 & 0 & 20 & 20 \\
\hline
\end{tabular}

This equation does not account for solar heating, or for the forced venting of heat through holes in the roof surface. The true thermal conductivity of the composite roof is also uncertain, as is the true internal temperature of the building. Nonetheless, the table gives a rough idea of the temperature changes induced by internal activity. As seen in the table, even in very hot summer conditions $\left(\mathrm{T}_{\text {air }}=35^{\circ} \mathrm{C}\right)$ the rooftop temperature is still $6{ }^{\circ} \mathrm{C}$ above ambient assuming a $60^{\circ} \mathrm{C}$ interior ceiling temperature. Since the thermal imagery is sensitive to temperature differences of a few Celsius degrees, this worst case gives confidence that the heating effects due to internal activity can be seen throughout the year.

\section{Solar Heating of Rooftops}

Equation 1 can be modified to account for solar heating by adding a term to the total heat load Qroof:

2)

$$
\begin{aligned}
& Q_{\text {roof }}=Q_{\text {sun }}+Q_{\text {int }}=Q_{\text {sun }}+\left(K \times\left(\frac{T_{\text {int }}-T_{\text {roof }}}{\Delta x}\right)\right) \\
& =Q_{\text {air }}=C \times\left(T_{\text {roof }}-T_{\text {air }}\right)+\varepsilon \sigma\left(T_{\text {roof }}{ }^{4}-T_{\text {arr }}{ }^{4}\right) .
\end{aligned}
$$

Here $\mathrm{Q}_{\text {sun }}$ is the absorbed solar radiation in Watts $/ \mathrm{m}^{2}$, with the other variables and constants defined as in Equation 1. For a horizontal surface, $Q_{\text {sun }}$ is a function of latitude, season, time of day, weather conditions and the solar absorptivity of the surface. Interpolation within tables of values of the average daily cloud-free exposure at the appropriate latitude and date ${ }^{15}$, gives approximate solar power rates at each hour during the time leading up to image acquisition. 
The true value of the solar absorptivity of the roof material is unknown for the present case. In general, the solar absorptivity of rough non-metallic surfaces such as gravel differs from their thermal emissivity, with representative ranges from $0.25-0.5$ for lightcolored surfaces. and 0.4-0.8 for darker surfaces ${ }^{16}$. Lower absorptivity values reduce the solar contribution significantly. However, whatever the actual absorptivity value, the solar contribution will not mask the $\sim 5-20^{\circ} \mathrm{C}$ temperature difference relative to background produced by internal activity alone.

Since the effect of wind is not taken into account in Equation 2, the value of $T_{\text {roof }}$ derived from it is not useful for comparison with the 1991 image in which high wind conditions prevail. The result should be more useful for comparison with the 1994 reconstructed temperature, where the effect of wind is noticeably smaller.

Table 6 shows the approximate solar power per square meter absorbed hourly during each hour until 9:45 A.M for the 1994 data, adopting extreme values of 0.25 and 0.8 for the value of the solar absorptivity. Table 7 shows the rooftop temperatures associated with each value of absorptivity, with the crude assumption that the total absorbed solar radiation is that calculated at the hour of image acquisition (the last column of numbers in Table 6). The air temperature is approximated by the reconstructed scene average temperature of $4^{\circ} \mathrm{C}$, from Table 3 .

Table 6 . The estimated absorbed solar power incident on flat roofs in the daytime hours before the 9:45 image acquisition time.

\begin{tabular}{|l|l|c|c|c|c|c|}
\hline Date & $\begin{array}{l}\text { Time of } \\
\text { sunrise }\end{array}$ & \multirow{2}{*}{$\begin{array}{c}\text { Solar } \\
\text { Absorptivity }\end{array}$} & \multicolumn{4}{|c|}{$\begin{array}{c}\text { Approximate number of hours } \\
\text { before image acquisition }\end{array}$} \\
\cline { 3 - 7 } & & 3 & 2 & 1 & 0 \\
\cline { 3 - 7 } & & & \multicolumn{4}{|c|}{$\begin{array}{c}\text { Hourly absorbed radiation } \\
\left(\mathrm{W} / \mathrm{m}^{2}\right)\end{array}$} \\
\hline Mar 12.1994 & $6: 48$ & 0.25 & 40 & 65 & 90 & 100 \\
& & 0.8 & 120 & 210 & 300 & 330 \\
\cline { 4 - 7 } & & & & & & \\
\hline
\end{tabular}


Table 7. The expected roof temperature $T_{\text {roof }}$ using Equation 2, compared with the average of the reconstructed values of the rooftop temperature from Table 3.

\begin{tabular}{|l|c|c|c|c|c|}
\hline Date & $\begin{array}{c}\text { Solar } \\
\text { Absorptivity }\end{array}$ & $\begin{array}{c}\mathrm{T}_{\text {int, }} \\
{ }^{\circ} \mathrm{C}\end{array}$ & $\begin{array}{c}\mathrm{T}_{\text {air, }}{ }^{\circ} \mathrm{C} \\
\text { (scene } \\
\text { average, } \\
1994, \text { from } \\
\text { Table 3) }\end{array}$ & $\begin{array}{c}\mathrm{T}_{\text {roof }}{ }^{\circ} \mathrm{C} \\
\text { (expected, } \\
\text { using } \\
\text { Equation 2) }\end{array}$ & $\begin{array}{c}\mathrm{T}_{\text {roof, }}{ }^{\circ} \mathrm{C} \\
\text { (typical } \\
\text { reconstructed } \\
\text { value, 1994, } \\
\text { from } \\
\text { Table 3) }\end{array}$ \\
\hline Mar 12, & 0.25 & 60 & 4 & 23 & 24 \\
\cline { 2 - 6 } 1994 & 0.8 & 60 & 4 & 34 & 24 \\
\hline
\end{tabular}

Comparing the first row of Table 7 with the first row of Table 5, I estimate that the internal heat and solar contributions to the rise in rooftop temperature are roughly comparable at this time of day.

As shown in the first row of Table 7, the lower value of the solar absorptivity gives a better match between the estimated and reconstructed roof temperature. Of course, this agreement is fortuitous, since the effects of wind and forced cooling have not been accounted for. However, the analysis confirms that a significant fraction of the heat load and temperature rise of the rooftops comes from internal activity.

\section{Cooling of Rooftops by the Wind}

By changing the heat transfer coefficient in Equation 2, I can roughly estimate the reduction in surface temperature due to wind. I assume that the heat transfer coefficient increases to $30 \mathrm{Watt} /\left(\mathrm{m}^{2}{ }^{\circ} \mathrm{C}\right)$, corresponding to a $6.7 \mathrm{~m} / \mathrm{sec}(15 \mathrm{mph})$ wind ${ }^{17}$. I also assume a background temperature of $-7^{\circ} \mathrm{C}$, characteristic of the 1991 data. The remaining constants are the same as above, with an assumed solar term of $330 \mathrm{Watt} / \mathrm{m}^{2}$ and absorptivity of 0.25 . As seen in Table 8 , the effect of wind is dramatic, lowering the rooftop temperature by about $15^{\circ} \mathrm{C}$. (Again, the close agreement with data is fortuitous.) However, the difference from background is still far greater than the few Celsius degree resolution of the LANDSAT platforms. 
Table 8. The effect of wind on the rooftop temperature.

\begin{tabular}{|c|c|c|c|c|c|}
\hline & $\begin{array}{c}\text { heat transfer } \\
\text { coefficient } \\
\left(\text { Watt } / \mathrm{m}^{2}{ }^{\circ} \mathrm{C}\right)\end{array}$ & $\mathrm{T}_{\text {int }}\left({ }^{\circ} \mathrm{C}\right)$ & $\begin{array}{c}\mathrm{T}_{\text {air }}\left({ }^{\circ} \mathrm{C}\right) \\
(\mathbf{s c e n e} \\
\text { average, } \\
1991, \text { From } \\
\text { Table 3 }\end{array}$ & $\begin{array}{c}\mathrm{T}_{\text {roof }}\left({ }^{\circ} \mathrm{C}\right) \\
\text { (expected, from } \\
\text { equation 2) }\end{array}$ & $\begin{array}{c}\left(\mathrm{T}_{\text {roof }}\left({ }^{\circ} \mathrm{C}\right)\right. \\
\text { (typical } \\
\text { reconstructed } \\
\text { value, 1991, } \\
\text { from Table 3) }\end{array}$ \\
\hline no wind & 10 & 60 & -7.7 & 27 & 11.5 \\
\hline $\begin{array}{c}\text { wind } \\
6.7 \mathrm{~m} / \mathrm{sec} \\
(15 \mathrm{mph})\end{array}$ & 30 & 60 & -7.7 & 10 & 11.5 \\
\hline
\end{tabular}




\section{Appendix II: The LANDSAT-5 Temperature Conversion Algorithm ${ }^{18}$}

The LANDSAT calibration procedure first converts the raw pixel value, an 8-bit integer, into a radiance value using a standard set of constants. Next the radiance value is converted to a temperature. For the radiance $\lambda,\left(\mathrm{mW} /\left(\mathrm{cm}^{2} \cdot \mathrm{sr} \cdot \mu \mathrm{m}\right)\right.$ we have:

$\lambda=\lambda_{\min }+\left(\frac{\lambda_{\max }-\lambda_{\min }}{q_{\max }}\right) * \mathrm{DN}=0.1238+0.00561 \mathrm{DN}$,

where $\lambda_{\min }, \lambda_{\max }$ are respectively the minimum and maximum radiance values from the scene header, $D N$ is the raw 8 bit integer band 6 digital count, $(0-255)$, and $q_{\max }=255$ is the maximum possible value of $\mathrm{DN}$.

The formula for converting the derived radiance value to a Kelvin temperature $T$ is:

$$
\mathrm{T}=\frac{\mathrm{K}_{2}}{\ln \left(\frac{\mathrm{K}_{1}}{\lambda}+1\right)},
$$

where $\lambda$ is the radiance, and the numerical constants are $\mathrm{K}_{1}=60.776 \mathrm{~mW} /\left(\mathrm{cm}^{2} \cdot \mathrm{sr} \cdot \mu \mathrm{m}\right)$ and $\mathrm{K}_{2}=1260.56 \mathrm{~K}$ for LANDSAT -5 data. 


\section{Appendix III: The Effects of Pixel Averaging and Resampling On the Temperature Profiles Of Process Building 326.}

The reconstructed temperatures of the process buildings are affected by pixel averaging across boundaries and by the resampling algorithm implemented by the supplier. As described above, the reconstructed temperature of building 326 in 1994 is lower than that of the other two buildings, while in 1991, the temperatures are within statistical error (see Table 4). It is important to understand the effects of pixel averaging and resampling on this building, to determine whether they can account for the temperature difference. If so, any actual correlation with the reduction in activity known from ground truth data could be obscured.

Here I roughly. estimate the combined effects of pixel averaging and the cubic convolution resampling algorithm. I use the geometry of the narrowest building, 326 as an example, because the combination of effects is likely to be largest in this building. The resultant error is about $2^{\circ} \mathrm{C}$ downward, with smaller downward shifts in buildings 330 and 333 . The net effect is less than $2{ }^{\circ} \mathrm{C}$, and is smaller than the $4{ }^{\circ} \mathrm{C}$ shift seen in the 1994 data between buildings 326 and 333. However, in combination with a nonuniform change in emissivity, it could account for much of the difference between buildings shown in Table 4 . The shift is clearly far too small to account for the $10-20^{\circ} \mathrm{C}$ difference of the buildings from background.

It is important to re-emphasize that for GDPs with sizes similar to the Portsmouth plant, both of the effects described below will be nearly absent for LANDSAT-7 type imagery, because of the smaller pixel size and different resampling method. The restrictions placed on the utility of the current LANDSAT -5 data set due to resampling and averaging will not be present for thermal satellites with resolution comparable to LANDSAT-7 and ASTER. 


\section{The Mixed Pixel Effect}

Prior to resampling, the raw LANDSAT-5 pixel covers a square on the Earth's surface $120 \mathrm{~m}$ on a side. A single $120 \mathrm{~m}$ thermal pixel is an area-weighted average of the radiance of all objects seen by the pixel. If a pixel crosses a building boundary, its associated temperature will be lowered due to the lower temperature of area surrounding the building. The formula for the resulting temperature is:

3) $T_{\text {measured }}=\sqrt[4]{A_{r} \cdot\left(T_{r}\right)^{4}+A_{b g} \cdot\left(T_{b g}\right)^{4}}$ 19

Here, $T_{\text {measured }}$ is the temperature reconstructed from the LANDSAT-5 image, $T_{r}$ is the true roof temperature, $T_{b g}$ is the background temperature, $A_{r}$ is the fraction of the pixel area covering the roof, and $A_{b g}$ is the fraction of pixel area covering the adjacent background.

As described earlier, the reconstructed temperature of the buildings is an average over a central set of pixels for each process building. For building $326,3028.5 \mathrm{~m}$ resampled pixels arranged in two columns in the center of the building contribute to the average, as shown in Figure 6. As seen in Figure 7, the resampled pixels in the data as received from the supplier are tilted by about 12 degrees with respect to the building orientation. For treatment of both the averaging and resampling effects, I make the following important assumption: the 12 degree tilt of the pixels with respect to the buildings is present in both the unresampled $(120 \mathrm{~m})$ and resampled $(28.5 \mathrm{~m})$ data.

To get a rough idea of the size of the pixel averaging effect alone, I consider a worst case placement of the $120 \mathrm{~m}$ pixels, in which about 30 percent of the pixel falls outside the building perimeter. In this case, using Equation 3 , gives a reduction in the measured temperature $T_{\text {measured }}$ compared to a true roof temperature $T_{\text {roof }}$ of about $1.5-2.5^{\circ} \mathrm{C}$, for true temperatures in the range from $20-30^{\circ} \mathrm{C}$ and a background temperature of $4{ }^{\circ} \mathrm{C}$. In the best case, when a single $120 \mathrm{~m}$ unresampled pixel spans both columns of resampled pixels used in the average, there is no mixed pixel effect. Due to the tilt in the pixel 


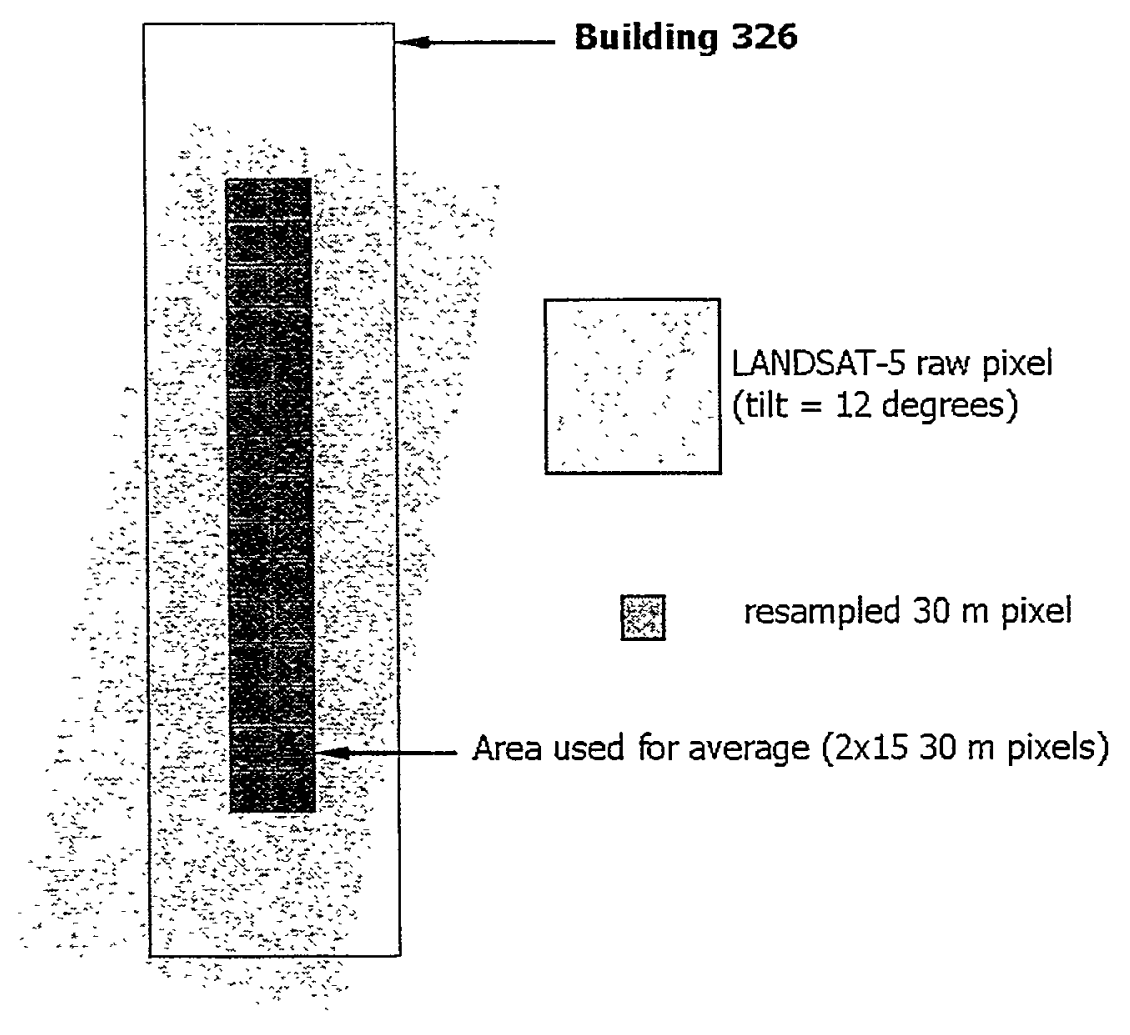

Figure 6. The pixels used for the average temperature measurement of the interior area of process building 326 .

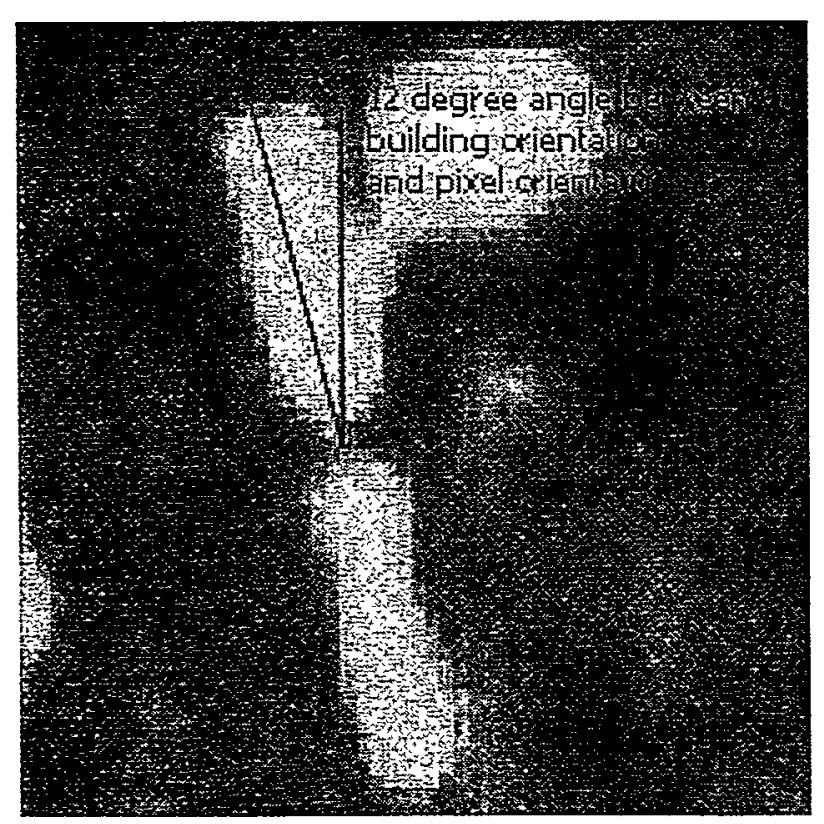

Figure 7. A closeup of the 1994 image, showing the resampled pixel granularity and the 12 degree tilt of the pixel relative to the building. 
orientation, the worst case averaging effect can occur in no more than about 15 of the 30 resampled pixels used in the average. As a result, the reduction in the rooftop temperature average due to the mixed pixel effect alone can be no greater than $\sim 1-2^{\circ} \mathrm{C}$.

\section{Resampling}

The radiance values of the $120 \mathrm{~m}$ pixels, shifted by the area-weighting process, are used as inputs to the resampling process, which introduces a second shift. The total shift induced in the rooftop average comes from the combination of these two effects.

The LANDSAT -5 images used in this study were resampled by the supplier using a cubic convolution algorithm described below. The resampling process divides the $120 \mathrm{~m}$ pixel into approximately 16 smaller pixels and assigns new radiance values to the new pixels in the manner to be described. In the following estimate, I use a resampled pixel size of 30 $\mathrm{m}$ rather than the actual $28.5 \mathrm{~m}$ value, and presume that any difference in the result caused by this change is small.

As stated above, I assume that both the unresampled $120 \mathrm{~m}$ and resampled $30 \mathrm{~m}$ pixels are tilted by 12 degrees with respect to the building vertical axis. This is a key assumption for the following analysis. For this orientation, the effect of resampling in building 326 is most pronounced in the transverse (East-West) direction. The effect of resampling in the longitudinal direction is correspondingly small and will be neglected in the following treatment.

Cubic convolution resampling takes 16 unresampled pixels that surround a resampled pixel as inputs, and calculates the value of the resampled pixel using a cubic polynomial.

For LANDSAT data, the following cubic convolution resampling algorithm is used ${ }^{20}$ :

4) $R(i, j)=c 1 \times R(i-1, j)+c 2 \times R(i, j)+c 3 \times R(i+1, j)+c 4 \times R(i, j)]$

where the coefficients $\mathrm{c} 1$ to $\mathrm{c} 4$ are given by: 
$\mathrm{cl}=-0.5|1+\Delta|^{3}+2.5|1+\Delta|^{2}-4|1+\Delta|+2$

c2 $=1.5|\Delta|^{3}-2.5|\Delta|^{2}+1$

$\mathrm{c} 3=1.5|1-\Delta|^{3}-2.5|1-\Delta|^{2}+1$

$\mathrm{c} 4=-0.5|2-\Delta|^{3}+2.5|2-\Delta|^{2}-4|2-\Delta|+2$

In the above equations, $\Delta$ is the value of the offset in the horizontal direction of the resampled pixel $(i, j)$ from the unresampled pixel $(i, j)(\Delta i$ in Figure 8$)$. In general, $0 \leq \Delta \leq 1$ : in the current case, the granularity of the $30 \mathrm{~m}$ pixels restricts the value of $\Delta$ to the discrete values $0.0 .25,0.5$, and 0.75 . The pixel definitions are as shown in Figure 8 .

This quantity is first calculated along the horizontal axis, for each value of $\mathrm{j}$ ranging from $j-1$ to $j+2$. The resulting 4 interpolated radiance values, are then used as inputs to equation analogous to Equation 4 to calculated a new radiance at $R\left(i^{\prime}, j^{\prime}\right)$, where $j$ is the longitudinal coordinate of the desired new pixel, and the vertical offset $\Delta j$ shown in Figure 8 is used. Here I neglect this last step, assuming that the four intermediate values $R\left(i^{\prime}, j-1 \ldots j+2\right)$ are numerically equal to the output value $R\left(i^{\prime}, j^{\prime}\right)$. This is just the mathematical consequence of ignoring the small change in radiance in the longitudinal direction for building 326 .

To calculate the input unresampled radiance values, I consider an idealized situation that approximates the actual data in 1994 , assuming a roof temperature of $22^{\circ} \mathrm{C}\left(295.15^{\circ} \mathrm{K}\right)$ and a background temperature of $4{ }^{\circ} \mathrm{C}\left(277.15^{\circ} \mathrm{K}\right)$. The area-averaged radiance values $R(i, j)$ are calculated from Equation 3, using the Kelvin temperatures as inputs.

Because of the 12 degree tilt in the pixel orientation with respect to the building, there is a correlation between $\Delta i$, the horizontal offset of the resampled pixel, and $A_{r}$ and $A_{b g}$, the fractions of roof area and background area that enter into calculation of the input pixel values in Equation 3. By considering two extreme cases, I can roughly estimate the net effect of resampling and pixel averaging. 


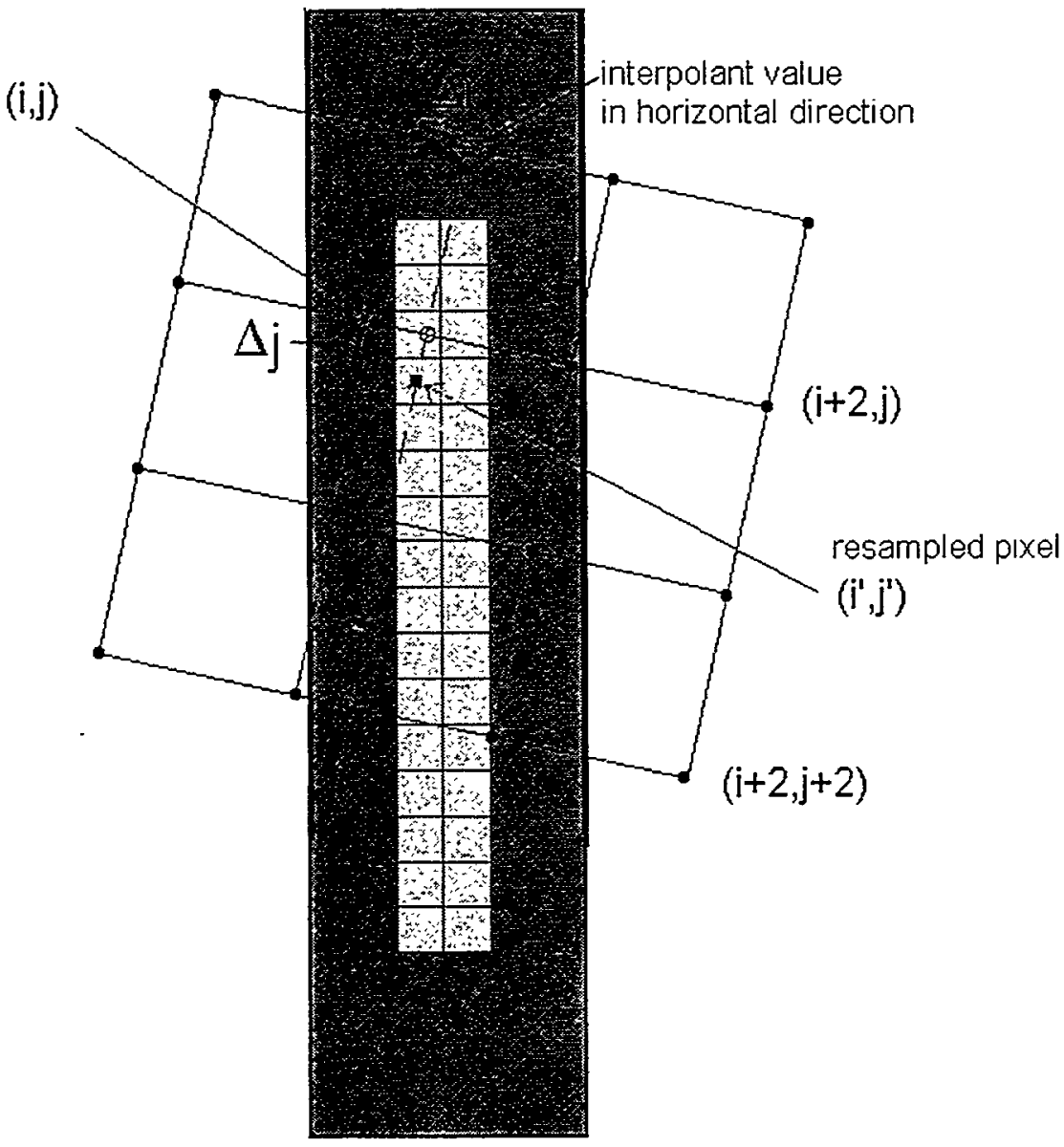

Figure 8. The unresampled $120 \mathrm{~m}$ pixel grid superimposed onto the $2 \times 15$ array of $30 \mathrm{~m}$ pixels at the center of building 326, used here to define the building average. $\Delta \mathrm{i}$ and $\Delta \mathrm{j}$ are the offsets along the horizontal and vertical grid axes (as measured in units of the unresampled pixel) from pixel (i,j) to the resampled pixel, (i,j'), shown as a black square. The four intermediate interpolants produced using Equation 4 are shown as open circles. These are again weighted using the cubic polynomial and the vertical offset $\Delta j$ to produce the final value of the radiance at $\left(i^{\prime}, j^{\prime}\right)$. 
For the case $\Delta i=0 ., R(i, j)$ is numerically equal to $R\left(i^{\prime}, j^{\prime}\right)$, i.e. the radiance of the resampled pixel is unchanged. Moreover, the mixed pixel effect is nearly absent, since the unresampled $120 \mathrm{~m}$ pixel, in this case centered by definition on an interior $30 \mathrm{~m}$ pixel, is almost completely contained within the building perimeter $\left(A_{r}=1, A_{b g}=0\right)$. Thus in this special case, the rooftop temperature is unaffected by either pixel averaging or resampling, so that the temperature for resampled pixels with $\Delta=0$. is equal to the nominal value of $22^{\circ} \mathrm{C}$.

The worst case occurs for $\Delta \mathrm{i}=0.5$, when the combined effects of pixel mixing and resampling conspire to produce a considerable downward shift. Again exploiting the correlation between the offset $\Delta i$ and the area fractions $A_{b g}$ and $A_{r, 1}$ estimate these fractions as approximately 0.8 and 0.6 respectively within pixel $(\mathrm{i}, \mathrm{j})$ and 0.6 and 0.8 respectively in the pixel $(i+1, j)$. With these parameters, the temperature of the resampled pixels is $18.5^{\circ} \mathrm{C}$.

Because of the tilt in pixel orientation, both of these cases must be present among the 30 pixels used for the rooftop average, with intermediate values present for the remainder of the pixels. Roughly, the overall effect is to produce a $2{ }^{\circ} \mathrm{C}$ downward shift in the building average over the resampled pixels.

For building 330, the narrow building directly to the north of building 326 , a downward shift will still be present, though somewhat smaller due to the greater width of the building. In Building 333, the effect of resampling is again smaller in the transverse direction due to the greater width, but the contribution in the longitudinal direction is greater, and the net result must again be downward based on the geometry. Without performing a detailed calculation, $2^{\circ} \mathrm{C}$ is a reasonable upper bound using the building 326 results. 


\section{Acknowledgments}

This research was supported by the Cooperative Monitoring Center at Sandia National Laboratories. Sandia is a multiprogram laboratory operated by Sandia Corporation, a Lockheed Martin Company, for the United States Department of Energy under Contract DE-AC04-94AL85000.

The author would like to thank Lynn Calvert, John Shoemaker and Sandy Childers at the Porstmouth plant for providing important information about plant operations. I also benefited greatly from discussions and editorial review by Tom Budge, George Baldwin, Frank Von Hippel and Marty Abrams. Finally, thanks are due to Bill Ballard and Doug Henson and Larry Brandt for facilitating the release of this report. The analysis, views, and opinions expressed herein are those of the author alone. 


\section{References}

1. http://geo.arc.nasa.gov/sge/landsat/landsat.html

2. LANDSAT satellite images have seven distinct spectral bands. Three of these are in the visible spectrum, two in the mid-infrared, and one each in the thermal infrared (10-12 $\mu \mathrm{m})$ and near infrared. The entire image covers a $170 \times 185 \mathrm{~km}$ area on the ground. $\sim 0.5^{\circ} \mathrm{C}$ resolution has been achieved in practice when atmospheric and emissivity effects are correctly accounted for. See for example, Wukelic et. al., "Radiometric Calibration of LANDSAT Thematic Mapper Thermal Band", Remote Sensing of the Environment, Vol. 28. 1989, pp. 339-347, in which LANDSAT thermal resolutions of less than $0.5^{\circ} \mathrm{C}$ are presented.

3. http://asterweb.jpl.nasa.gov/asterhome.

4. http://asterweb.jpl.nasa.gov/asterdata/authorization/default.htm.

5. A technology now under development, atomic vapor laser isotope separation (AVLIS), has a specific energy consumption approximately 100 times lower than that of gaseous diffusion. Although no plants of this type have yet been built, they would be all but impossible to identify with low-resolution satellite imagery.

6. Defense Intelligence Agency, People's Republic of China Nuclear Weapons Employment Policy and Strategy, 1972. http://www.fas.org/irp/dia/product/prc 72/app e.htm.

7. Personal Communication, Lynn Calvert, Lockheed Martin Utility Services, July 1999.

8. T. Lillesand, R. Kiefer, Remote Sensing and Image Interpretation, (New York: John Wiley \& Sons, 1987) p.403.

9. Personal Communication, Lynn Calvert, Lockheed Martin Utility Services, July 1999.

10. M. Molbert, "The Eurodif Program", in Recent Developments in Uranium Enrichment, ed. J.R. Merriman and M. Benedict, Vol. 78 (NY: American Institute of Chemical Engineers, 1982) p. 221. This reference quotes a below-ceiling temperature of $80^{\circ} \mathrm{C}$ for the Tricastin plant.I conservatively adopt a lower value of $60^{\circ} \mathrm{C}$ in all estimates.

11. I used the LANDSAT archives at http://origin.eosat.com.

12. B. Clark, "New Lookup Tables", EOSAT LANDSAT Technical Notes, No. 1. August 1996, p. 4.

13. D. E. Gibbons, G. E. Wukelic, J. P. Leighton, M. J. Doyle, "Applicaton of Landsat Thematic Mapper Data for Coastal Thermal Plume Analysis at Diablo Canyon", Photogrammetric Engineering and Remote Sensing, Vol. 55, No. 6, June 1989, pp. 903909.

14. M. Ozisik, Basic Heat Transfer, (New York: Mcgraw Hill, 1977) p. 8.

15. J. A. Duffie, W. A. Beckman, Solar Engineering of Thermal Processes, (New York: John Wiley and Sons, 1980), Table 2.5.1, p. 44, and Table 2.13.1 p. 78.

16. Ray E. Bolz, George L. Tuve, Eds., Handbook of Tables for Applied Engineering Science, (Cleveland: CRC Press, 1973) Tables 2-9 and Table 2-10, p. 212.

17. Ibid., p. 539.

18. B. Clark, op. cit. 
19. The quartic dependence on temperature is due to the Stefan-Boltzmann law relating spectral radiance to temperature: $R=\sigma T^{4}$, where $R$ is the radiant energy density, $\sigma$ is the Stefan-Boltzmann constant and $\mathrm{T}$ is the absolute temperature.

20. The algorithm shown here is a special case of a general algorithm known as a parametric cubic convolution (PCC) algorithm, with a single parameter $\alpha$. For LANDSAT data, the value of $\alpha$ is -0.5 . The general algorithm can be found in John Richards, Remote Sensing Digital Image Analysis, An Introduction (New York: Springer Verlag, 1993), p. 350. 


\section{Distribution:}

$1 \quad$ Frank Von Hippel

Center for Energy and the Environment, $\mathrm{H}-102$

Engineering Quadrangle

Princeton University

Princeton, NJ 08544

1 Lisbeth Gronlund

Union of Concerned Scientists

2 Brattle Sq.

Cambridge, MA, 02238

1 Tom Budge

Earth Data Analysis Center

University of New Mexico

Bandelier West, Room 111

Albuquerque, NM 87131-6031

1 MS 1372 George Baldwin, 5324

1 MS 1373 Arian Pregenzer, 5321

1 MS 9001 Mim John, 8000

Attn: R. Wayne, 2200

J. Vitko, 8100

B. McLean, 8300

P. Smith, 8500

M. Dyer, 8700

K. Washington, 8900

D. Crawford, 9900

1 MS 9007 Doug Henson, 8400

1 MS 9202 William Ballard, 8418

1 MS $9201 \quad$ Marty Abrams, 8114

1 MS $9201 \quad$ Larry Brandt, 8112

1 MS 9214 Vipin Gupta, 16000

10 MS 9214 A. Bernstein, 8418

3 MS 9018 Central Technical Files, 8940-2

1 MS 0899 Technical Library, 4916

1 MS 9021 Technical Communications Department, 8528/

Technical Library, MS 0899, 4916

1 MS 9021 Technical Communications Department, 8528 For DOE/OSTI 